IZA DP No. 5048

Testing the 'Brain Gain' Hypothesis: Micro Evidence from Cape Verde

Catia Batista

Aitor Lacuesta

Pedro C. Vicente

July 2010 


\title{
Testing the 'Brain Gain' Hypothesis: Micro Evidence from Cape Verde
}

\author{
Catia Batista \\ Trinity College Dublin \\ and IZA \\ Aitor Lacuesta \\ Bank of Spain \\ Pedro C. Vicente \\ Trinity College Dublin, \\ CSAE-University of Oxford and BREAD
}

Discussion Paper No. 5048

July 2010

IZA

P.O. Box 7240

53072 Bonn

Germany

Phone: +49-228-3894-0

Fax: +49-228-3894-180

E-mail: iza@iza.org

Any opinions expressed here are those of the author(s) and not those of IZA. Research published in this series may include views on policy, but the institute itself takes no institutional policy positions.

The Institute for the Study of Labor (IZA) in Bonn is a local and virtual international research center and a place of communication between science, politics and business. IZA is an independent nonprofit organization supported by Deutsche Post Foundation. The center is associated with the University of Bonn and offers a stimulating research environment through its international network, workshops and conferences, data service, project support, research visits and doctoral program. IZA engages in (i) original and internationally competitive research in all fields of labor economics, (ii) development of policy concepts, and (iii) dissemination of research results and concepts to the interested public.

IZA Discussion Papers often represent preliminary work and are circulated to encourage discussion. Citation of such a paper should account for its provisional character. A revised version may be available directly from the author. 


\section{ABSTRACT \\ Testing the 'Brain Gain' Hypothesis: Micro Evidence from Cape Verde*}

Does emigration really drain human capital accumulation in origin countries? This paper explores a unique household survey purposely designed and conducted to answer this research question. We analyze the case of Cape Verde, a country with allegedly the highest 'brain drain' in Africa, despite a marked record of income and human capital growth in recent decades. Our micro data enables us to propose the first explicit test of 'brain gain' arguments according to which the prospects of own future migration can positively impact educational attainment. According to our results, a 10pp increase in the probability of own future migration may improve the average probability of completing intermediate secondary schooling by $8 \mathrm{pp}$ for individuals who do not migrate before age 16. Strikingly, this same 10pp increase may raise the probability of completing intermediate secondary schooling by $11 \mathrm{pp}$ for an individual whose parents were both non migrants when the educational decision was made. Our findings are robust to the choice of instruments and econometric model. Overall, we find that there may be substantial human capital gains from lowering migration barriers.

JEL Classification: F22, J24, O12, O15

Keywords: brain drain, brain gain, international migration, human capital, effects of emigration in origin countries, household survey, Cape Verde, sub-Saharan Africa

Corresponding author:

Catia Batista

Department of Economics

Trinity College Dublin

Dublin 2

Ireland

E-mail: catia.batista@tcd.ie

\footnotetext{
* We would like to thank helpful comments and suggestions on this and earlier drafts by the editor Gordon Hanson, two anonymous referees and to a number of participants in many seminars and conferences. We are indebted to Paul Collier for providing initial encouragement for this research project. We acknowledge financial support from the ESRC-funded Global Poverty Research Programme (GPRG) for the tailored household survey conducted in Cape Verde on which this paper is based. We are indebted to the dedicated team of local enumerators with whom we worked, and to Deolinda Reis and Francisco Rodrigues at the National Statistics Office of Cape Verde. Research assistance was provided by Mauro Caselli, under the financial support of the George Webb Medley Fund at the Department of Economics of the University of Oxford.
} 


\section{Introduction}

The last decades witnessed striking growth in international migration flows. ${ }^{1}$ In particular, the international movement of the highly educated experienced an impressive surge: according to Beine et al. (2008), from 1990 to 2000, there was a $63.7 \%$ increase in the number of highly-skilled immigrants residing in OECD countries (to a stock of 20 million), whereas the number of unskilled immigrants had only increased by $14.4 \%$ in the same ten years. This extraordinary trend has brought renewed interest and significance to the old 'brain drain' debate.

Concerns about 'brain drain' were introduced in the late 1960s and 1970s, and soon became well rooted in the economics literature. 'Brain drain' became a general label for the depressing effects arising from the loss of the most skilled national citizens in a country. In the 1990s, however, a new strand of theoretical literature proposed the 'brain gain' hypothesis: according to this proposition, it is possible that the outflow of educated migrants (and the possibility of own future migration in particular) can lead to a net increase in the origin country's stock of human capital. ${ }^{3}$

Despite the existing abundant theoretical literature on the 'brain drain' theme, the empirical literature has lagged until recently. This is due, at least partly, to data unavailability on the skill content of migration flows. Indeed, the dataset assembled by Docquier and Marfouk (2006) opened an avenue of renewed interest in the theme, prompting new research to verify and qualify the brain gain hypothesis across countries and over time (notably, Faini, 2006; Ozden and Schiff, 2006; and Beine et al. 2007, 2008). In our opinion, what remains to be done in this literature is, importantly, testing this hypothesis at the micro level - i.e. to examine explicitly whether the probability of own, future migration improves individual educational attainment. This is precisely the purpose of our paper.

In order to answer our research question, we make use of a new dataset: a tailored household survey conducted by the authors in Cape Verde in 2006. Cape Verde is a very interesting country for our purposes as it displays the highest 'brain drain' rate in the African continent, ${ }^{4}$ and yet also presents a fast

\footnotetext{
${ }^{1}$ Chiswick and Hatton (2003) offer a detailed description of this historical evolution and underlying mechanisms.

${ }^{2}$ Scott and Gruber (1966) and Bhagwati and Hamada (1974) were the main proponents for the 'brain drain' theories. The 'brain drain' effects presumably include the disappearance of a critical mass in production, research, public services (notably health and education) and political institutions, which could potentially be magnified by positive human capital externalities, or complementarities with factors of production or total factor productivity. In addition, massive emigration of the most educated could entail fiscal losses due to foregone revenues from public education of those who emigrate.

${ }^{3}$ This theory was put forward by Mountford (1997), Stark et al. (1997, 1998) and Vidal (1998). It proposed that a 'brain gain' could happen if expected returns to education increased when emigrating (as would be the case if host countries have higher returns to education than origin countries) and enough skilled individuals eventually decided not to emigrate.

${ }^{4}$ Our source is Docquier and Marfouk (2006), who report the 'brain drain' rate to be $67.5 \%$. 'Brain drain' is defined as the fraction of highly educated Cape Verdean nationals who reside abroad.
} 
growing stock of human capital, at least since $1990 .{ }^{5}$ These are apparently contradictory facts under the light of traditional 'brain drain' theories, which point to the possibility of a 'brain gain' in this instance.

In our empirical analysis, we are able to estimate the effect of the own future migration probability on education decisions because our data include the full histories of all household members, including those of current migrants, for whom we know characteristics at the time educational choices were made. In doing so, we assume that individuals who reside in Cape Verde decide around age 12 whether to complete a non-compulsory intermediate level of secondary schooling. At that point in time, they have certain information about their prospects of future emigration - which may or not happen in the future. In our regressions, our individual unit of observation are dependents aged between 16 and 30 years of age, who never emigrated before age 16 - thereby ensuring that their decision to complete schooling or not is made before migration. For this subset, we examine the educational impact of the own probability of future migration, which corresponds to testing the original 'brain gain' hypothesis. Our baseline results point to a 10pp increase in the probability of own future migration improving the average probability of completing intermediate secondary school by around 8pp. If we focus on those dependents whose parents were both non-migrants when educational decisions are made, this effect increases to $11 \mathrm{pp}$. These results are robust to the choice of instruments and econometric model.

In order to give precise meaning to our econometric estimates, we use a simultaneous equation model of migration and education decisions to simulate the behavior of an economy hit by changes in migration barriers - e.g. intensified immigration restrictions in destination countries. In particular, we are able to measure the effects of this counterfactual exercise on migration decisions and on the educational attainment of both non-migrants and of migrants - for which purpose we complement our survey data with information from censuses of the main international destinations of Cape Verdean emigrants. Our results show that a rise in migration barriers has non-linear effects (the elasticity of educational responses to changes in migration seems to increase with the size of the shock) with differential impact on migrants and non-migrants. For instance, a shock decreasing migration by $9 \mathrm{pp}$, reduces the educational attainment of non-migrants by $7 \mathrm{pp}$ (implying an elasticity of 0.21 ), and that of migrants by only $2 \mathrm{pp}$ (implying an elasticity of 0.06 ). This evidence supports the importance of the 'brain gain' mechanism, even after we account for the educational upgrade by early migrants who may return when migration policies are made more restrictive.

Our work is related to two main strands in the migration literature. The first is the previously mentioned, cross-country empirical work on the 'brain gain' hypothesis as defined at a macro level. ${ }^{6}$ This approach

\footnotetext{
${ }^{5}$ Batista et al. (2007) show that, over the period 1990-2005, the stock of human capital in Cape Verde grew at an annual rate of $3.5 \%$. In addition, according to their growth accounting results, human capital accumulation is the aggregate input that accounts for most of the excellent growth performance of the Cape Verdean economy over those 15 years.
} 
has the advantage of distinguishing between countries that are more or less affected by 'brain gain' indeed, only in poorer countries with sufficiently low emigration rates does human capital accumulation seem to benefit from skilled emigration. However, the simplistic definition of 'brain gain' at the macro level (as a country's native tertiary schooling growth due to migration of skilled workers) misses potentially important individual heterogeneity and is, by design, incapable of identifying the channels through which these positive effects work. Our study overcomes these limitations by using micro data from our tailored household survey, which enables us to explicitly test and find supportive evidence to the own probability of future migration channel - i.e. the original 'brain gain' hypothesis.

This paper is also related to microeconometric work on the effects of having a migrant in the household on the educational attainment of Mexican children, as in Hanson and Woodruff (2002) and McKenzie and Rapoport (2006). Unlike these studies, we model the simultaneous decisions of educational attainment and own migration, which allows us to test explicitly for the original 'brain gain' hypothesis. In Hanson and Woodruff (2002) and McKenzie and Rapoport (2006) it is not that clear which mechanism is underlying the positive correlation between parental emigration and children's education.

The remainder of the paper is organized as follows. In the next section, we begin by presenting a brief overview of Cape Verde. We then proceed, in section 3, by presenting our data sources, namely the household survey we use in our empirical work, including descriptive statistics, and our estimates for 'brain drain' in Cape Verde. In section 4, we present the econometric model and identification strategy. In section 5, the main 'brain gain' positive empirical findings are presented and discussed, along with robustness checks. In the following section, counterfactual scenarios are computed under which barriers to migration are increased, and the effects on migration and education are discussed. Section 6 empirically examines briefly the possible reasons why a higher likelihood to emigrate may promote increased educational attainment. Finally, section 7 summarizes our findings and presents policy implications.

\section{Cape Verde: a short introduction to the country}

Cape Verde is a nine-island country with 441,000 inhabitants, according to the 2000 census. It became independent from Portugal in 1975 and has been a stable democracy since 1991. The country is currently ranked by the World Bank as a "Lower Middle-Income" economy, and had a GDP per capita of 5900 PPP-Adjusted Dollars in 2003, according to Heston et al. (2006).

\footnotetext{
${ }^{6}$ Notably, Faini (2006) and Beine et al. (2007, 2008).
} 
Cape Verdean economic growth clearly exceeded the Sub-Saharan African average of 0.6\% GDP per capita growth over 1980-2004 (again according to Heston et al., 2006). Indeed, it was the third fastest country in terms of per capita growth out of the 45 sub-Saharan countries in Heston et al. (2006), after Equatorial Guinea (11\% average annual growth rate) and Botswana (5\%). These countries are both rich in natural resources and exports account for a large fraction of their GDP (47\% and 55\%, respectively). Unlike them, Cape Verde stands out growing at an average annual rate of 4.4\% (4.1\% over 1981-1990, $5.8 \%$ over 1991-2000) but with exports accounting for only $20 \%$ of its GDP and no natural resource abundance - rather the opposite, as droughts and famines were recurrent in the country's history.

Droughts and famines indeed prompted the massive emigration phenomenon that has characterized this country for many decades. According to our calculations, ${ }^{7}$ there are more than 100.000 Cape Verdean currently residing abroad, or about 19\% of all nationals. Docquier and Marfouk (2006) estimate the percentage of the highly educated labor force of Cape Verde living abroad at $67.5 \%$ - the largest such number in the African continent. In addition, the magnitude of international remittances received in Cape Verde is impressive: as shown in Figure 1, these flows account for 16\% of GDP on average over 1987-2003 (according to the World Bank, 2006b). Moreover, we should note that these are official numbers, likely underestimated as they do not include informal channels. These figures are again the largest in sub-Saharan Africa and translate the especially important role of remittances for the country, particularly given the relative magnitude when compared to aid and foreign direct investment inflows.

A final note is deserved to the educational system in Cape Verde, which potentially provides the supply side restriction to our question of interest. This system functions remarkably well, particularly for subSaharan African standards, at least before the university level. Primary (six compulsory years of schooling) and secondary schooling (six further years grouped in three levels) are widely available at the local level (there is at least one secondary school per municipality, even more so at the primary level). Higher education institutions only started working in the country in 1995 and are located in the capital island. The following diagram illustrates the age of a child when the household decides whether to keep her in school or not.

\footnotetext{
${ }^{7}$ To compute the number of Cape Verdean living abroad we sum the number of Cape Verdean in the censuses of the main destination countries for which we have available data (Portugal, United States, France, Netherlands, Luxembourg, Italy and Spain), and divide it by 0.92 (emigrants to these destination countries represent, according to our survey, $92 \%$ of all emigrants from Cape Verde in the last five years).
} 


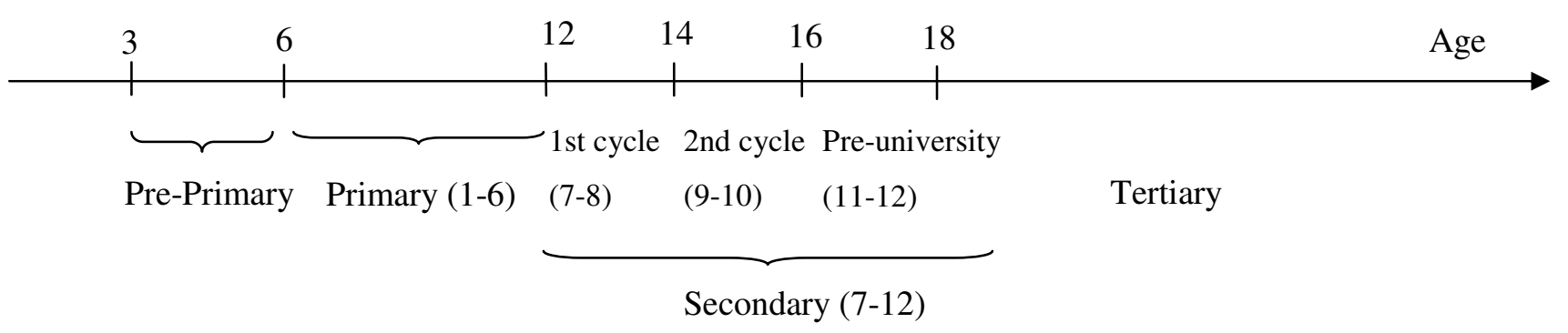

\section{Data description}

\section{Data sources}

Our empirical work is mainly based upon a household survey on migration and the quality of public services designed to answer our research questions. The survey was conducted in Cape Verde from December 2005 to March 2006 by the CSAE at the University of Oxford. It was based on a representative sample of 1066 resident households (including both non-migrants and return migrants), and also provides information on a large sample of current emigrants. The questionnaire included two modules: one on perceived quality/corruption of public services; and the other on migration characteristics of the household. The household respondent (someone aged at least 30 years old) was asked to specify socio-demographic characteristics of all members of the household, including children who already live elsewhere. Moreover, he was asked to characterize all migration spells within the household, including who emigrated, where and when. Finally, there were some questions regarding the economic situation of the household such as living standards, income or whether any member of the family received remittances in the previous year. More information regarding the survey can be found in Appendix A.

As detailed in the following sections, we complement our dataset with several secondary data sources. In particular, we make use of the Cape Verde Census (INE 2002); the Income and Expenditure Household Survey (INE 2004), designed and conducted by the Cape Verde National Statistics Office (INE) in 2001-2002 under the sponsorship of the World Bank; and several censuses from the main destination countries to Cape Verdean migrants, available from Ruggles et al. (2004).

\section{General descriptive statistics}

In this section we briefly characterize the information from our household survey, emphasizing the comparability of our data with those of other sources.

Our survey seems to accurately depict the migration reality in Cape Verde except for the fact that it misses a particular type of emigrants: those who did not leave family behind. In order to correct for the potential selection bias induced by this limitation, we use census data characterizing Cape Verdean 
immigrants in the main destination countries. ${ }^{8}$ This information allows us not only to estimate the stock of emigrants abroad, but also to examine observable characteristics of emigrants, such as gender, age and education.

As can be observed from Table 1, the figures for migration flows for the period 2000-2005 in our survey are relatively close to those presented in the INE (2002) census for the period 1995-2000. Table 2 displays the main destinations for Cape Verdean emigrants. According to both our survey and the INE (2002) census, Portugal and the USA account for respectively about 55\% and $20 \%$ of the total emigration flows.

Table 3 compares information from IPUMS (Ruggles et al., 2004) on the number, gender and age of Cape Verdean that reside in France, Netherlands, Luxembourg, Italy and Spain, with the same information for those who reside in Portugal and the USA. ${ }^{9}$ It is evident that the stock of emigrants abroad coming out of the survey is smaller than our estimates based on the censuses of the main international destinations. This mismatch reflects the fact that several whole and reunited families reside abroad. These families cannot, by design, be included in our sample, contrary to what happens in the censuses of the foreign countries where they live. The results show that there are minor gender differences, but that the age profile of emigrants to all destinations is remarkably similar. As could be expected, and still according to Table 3, the age profile of emigrants in our survey and that coming from the censuses is similar, except for the fact that our survey tends to exaggerate the fraction of individuals aged 21-30 years old, which are likely to be emigrants leaving their (interviewed) families behind. Conversely, children aged 10 years old or less, who likely emigrated with their whole families, are under-represented in our survey. Also unsurprisingly, the results in Table 3 show that, relative to residents in Cape Verde, emigrants tend to be slightly disproportionately males and in their primeworking years. Return migrants are strongly disproportionately males and aged more than 50 years old.

\section{Traditional measures of 'brain drain'}

We now turn to characterizing the educational attainment of Cape Verdean emigrants relative to residents in the country. This is directly related to conventional narrow measures of 'brain drain', defined as the proportion of highly-skilled Cape Verdean living abroad.

Table 4 describes the educational attainment of Cape Verdean individuals aged at least 25 years old who reside in Portugal and the United States (representing nearly 75\% of all Cape Verdean emigrants). We observe that the educational attainment of emigrants differs in the censuses and in our survey. Namely,

\footnotetext{
${ }^{8}$ The main destination countries, accounting for practically all Cape Verdean migrants, for which we have available census data are: Portugal, United States, France, Netherlands, Luxembourg, Italy and Spain. We used the 5\% sample of the American census from IPUMS (Ruggles et al., 2004). Information on Cape Verdean in Portugal was provided by the National Statistics Office of Portugal and information for other European countries was taken from Eurostat.

${ }^{9}$ According to our survey, $92 \%$ of all emigrants from Cape Verde migrate to these countries. We are, therefore, confident of capturing most of the emigrants.
} 
the survey displays a larger fraction of emigrants with higher education. This is probably due to the fact that the survey misses information about complete household emigration, thereby increasing the relative weight of those individuals who emigrated alone with the purpose of pursuing higher education. We will therefore use data from the censuses as our source in measuring 'brain drain'.

According to the census data characterizing emigrants to both Portugal and the United States, there seems to be evidence of positive selection of migrants. Indeed, emigrants are disproportionately concentrated in middle and high levels of education (i.e. completion of at least 9 grades) relative to the non-migrant population. This disproportion is particularly high for emigrants who hold a university degree: $6.65 \%$ of emigrants, relative to only $3.40 \%$ of residents in Cape Verde.

Analyzing the information available for each of the two main destination countries, we uncover finer patterns of emigrant selection than those provided by aggregate numbers. Actually, there seems to be clear positive selection only for emigrants to the United States. Except at the university level, the educational attainment of emigrants residing in Portugal is actually lower than that of residents in Cape Verde. ${ }^{10}$ Given these differences across countries, it is not obvious how to approximate the educational attainment of the residual $25 \%$ of emigrants for which no educational data are available (mainly residing in France). We opt for the conservative assumption (in the sense that it yields maximum 'brain drain') that the residual emigrants have the same educational attainment as emigrants residing in the United States. The results of this assumption are presented in the fourth column of Table 4.

With this distribution of emigrant educational attainment in hand, we can now compute a measure of 'brain drain'. The measure traditionally used in the literature is the one proposed by Docquier and Marfouk (2006), i.e. the fraction of Cape Verdean university degree holders residing abroad. Using this definition and according to our data displayed in Table 4, the 'brain drain' in Cape Verde is $40 \%$. This number is much lower than the $67.5 \%$ reported by Docquier and Marfouk (2006), who provide the only existing numbers for 'brain drain' in Cape Verde. ${ }^{11}$ Most likely this difference is due to Docquier and Marfouk (2006)'s source of data on educational attainment in Cape Verde, ${ }^{12}$ in addition to discrepancies in the classification of educational degrees, particularly the 'high-skilled' ${ }^{13}$ Since the proportion of high-skill individuals is low among Cape Verdean, small differences in the classification of 'high-skill' are potentially capable of producing large differences in measuring 'brain drain'. For this reason, we

\footnotetext{
${ }^{10}$ This finding is consistent with a lower cost of emigration to Portugal relative to the United States, perhaps because of the common language, shorter geographical distance or longer emigration tradition.

${ }^{11}$ Carrington and Detragiache (1998) and Collier et al. (2004) provide numbers for several African countries, but not for Cape Verde.

${ }^{12}$ For most developing countries, Docquier and Marfouk (2006) use Barro and Lee (2001) as their source of information on educational attainment. This is missing for Cape Verde, and the criterion indicated for these cases is to use "neighboring countries".

${ }^{13}$ In Docquier and Marfouk (2006) the highly-skilled group includes all those who attended university, even if they did not complete a degree. Comparability of classifications of educational degrees in Cape Verde, the US and Portugal is discussed in Appendix B.
} 
propose to consider alternative measures of 'brain drain', namely focusing on groups with relatively higher weight in the population. For instance, the probability of emigration given at least an intermediate secondary level is $43 \%$, and that for Docquier and Marfouk (2006) is $44 \%$.

A final qualification regarding the traditional brain drain measures has to do with potential educational upgrading after migration. The magnitude of this phenomenon will likely affect 'brain drain' numbers. Indeed, $20 \%$ of immigrants from Cape Verde in the United States arrived before age 10 and they subsequently present higher educational degrees. Migrating early in life affects the educational attainment in destination countries. However, it is very difficult to distinguish between the fraction of the difference that is attributed to unobserved heterogeneity and the fraction that is attributed to the fact that those individuals are entering in a different educational system. This possibility can be explored by switching the educational attainment of those migrants who emigrate early in life with the educational attainment of those with same characteristics departing later. Batista et al. (2007) show that important differences between migrants and non-migrants remain nevertheless.

\section{Econometric model and identification strategy}

The hypothesis of 'brain gain' suggests that the mere possibility of one's migration in the future may improve his or her educational attainment in the origin country even if this person ends up never migrating. In this section, we propose an econometric model and methodology to identify this 'brain gain' effect, i.e. to explicitly estimate the impact of the own future probability of migration on schooling decisions in Cape Verde.

\section{Econometric model}

In order to estimate this 'brain gain' effect, we propose the following latent variable model. There are three latent variables $S^{*}, M^{*}(a)$ and $M^{*}$, which govern, respectively, the decisions on: educational attainment, $S$; (future) migration decision made at age $a, M(a)$, when the decision of completing education is also made; and actual migration decision, $M$, made at the age of actual migration. These choices may be represented in a timeline in the following way:

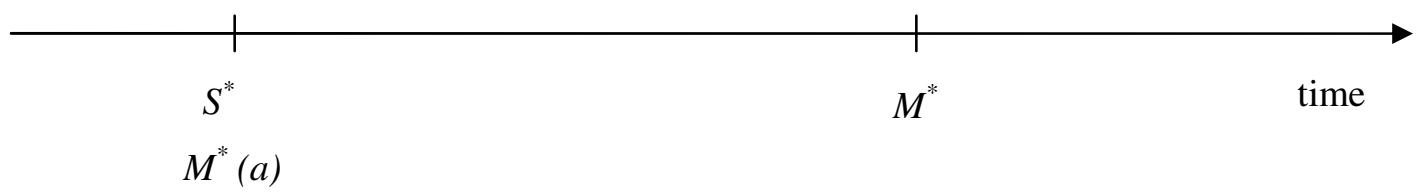

While the first two latent variables, $S^{*}$ and $M^{*}(a)$, are known simultaneously, the third one, $M^{*}$, may be thought of as an update to $M^{*}(a)$ at some point in the future: 


$$
\begin{array}{lll}
S_{i}=1\left(S_{i}^{*} \geq 0\right) & \text { with } & S_{i}^{*}=\alpha_{0}+\alpha_{1} M_{i}^{*}(a)+\alpha_{2}{ }^{\prime} X_{i}+\varepsilon_{s i} \\
& M_{i}^{*}(a)=\beta_{0}+\beta_{1} S_{i}^{*}+\beta_{2}{ }^{\prime} Y_{i}+\varepsilon_{m(a)_{i}} \\
M_{i}=1\left(M_{i}^{*} \geq 0\right) & \text { with } & M_{i}^{*}=M_{i}^{*}(a)+\varepsilon_{m i}
\end{array}
$$

Basically, the idea behind (1) - (3) is that at age $a$ individual $i$ makes two human capital investment decisions: she decides whether it is worthwhile to invest in further education or not and whether it is worthwhile to migrate or not. According to these rules, child $i$ will acquire education $\left(S_{i}=1\right)$ as long as the education latent variable $S_{i}^{*}$ is non-negative. Similarly, migration in the future will occur $\left(M_{i}=1\right)$ as long as the respective latent variable is non-negative, i.e. $M_{i}^{*}=M_{i}^{*}(a)+\varepsilon_{m i} \geq 0$.

The latent variable governing the education decision, $S_{i}{ }^{*}$, depends on several factors $\left(X_{i}\right)$ that potentially vary at the individual, household and regional levels. In addition, it is also influenced by the determinants of the own migration decision at the date schooling choices are made, $M_{i}{ }^{*}(a)$. This latent variable in turn depends on several covariates $\left(Y_{i}\right)$ that potentially also include individual, household and regional characteristics, and depends in addition on the determinants of the educational decision, $S_{i}^{*}$. In the future, however, regardless of the individual migration plans at age $a$, there may be unexpected shocks $\left(\varepsilon_{m i}\right)$ that impact the realized actual migration decision, $M_{i}$, as described in (3).

Mathematically, the three latent variables depend on vectors of variables $X_{i}$ and $Y_{i}$ which include individual, family, and locality-level characteristics of child $i$ and additive random error terms, $\varepsilon_{s i}, \varepsilon_{m(a) i}$ and $\varepsilon_{m i}$, which may be correlated. For example, it is possible that individual $i$ has an innate ability to learn, which could decrease both the costs of acquiring education and of migrating (e.g. if this ability facilitates the study of foreign languages and integration in foreign communities).

Model (1) - (3) presents a practical problem if one is interested in estimating its parameters: we do not observe the migration decision at age $a$, but only the actual migration decision realized at some point in the future, $M_{i}$. This problem occurs even if one is only really interested in estimating $\alpha_{1}$. In order to overcome this problem, we can rewrite the previous model as follows:

$$
\begin{array}{llr}
S_{i}^{*}=\alpha_{0}+\alpha_{1}{ }^{\prime} M_{i}^{*}+\alpha_{2}{ }^{\prime} X_{i}+\varepsilon_{1 i} & \text { where we observe } & S_{i}=1\left(S_{i}^{*} \geq 0\right) \\
M_{i}^{*}=\beta_{0}+\beta_{1}{ }^{\prime} S_{i}^{*}+\beta_{2}{ }^{\prime} Y_{i}+\varepsilon_{2 i} & \text { where we observe } & M_{i}=1\left(M_{i}^{*} \geq 0\right)
\end{array}
$$

\section{Identification strategy}

Under this framework, our 'brain gain' test will depend crucially on the value taken by parameter $\alpha_{1}$. Several estimation issues arise in its estimation. First, as previously discussed, there may be unobserved characteristics of the individual that simultaneously make her both more likely to emigrate in the future 
and more likely to get a higher educational attainment. Second, there is likely reverse causality, i.e. this individual may emigrate with a higher likelihood if she is more educated, for example. We therefore need exclusion restrictions on $\mathrm{X}$ with respect to $\mathrm{Y}$ in order to identify our parameter of interest. In particular, we need variables that affect the migration decision and are known at the time the education decision is made, but which do not directly affect this education decision. For this purpose, we exploit the full history of migration in the household, which we have available from our survey, and propose that the full actual duration (as measured at the date of the survey) of the longest migration spell in the family that started when the child is aged 12 or less years old (which we will simply label in the rest of the paper as "family migration duration at age 12") is used as an instrument in our baseline results. ${ }^{14}$ The length of the family migration spell provides us with information regarding the success of the closest migration experience to the child. Indeed, longer migration spells in the household likely reflect more successful migration experiences that should translate into deeper access to migrant networks. This network access should help facilitate migration for other household members. In contrast, a short duration of family migration might be consequence of a failure in the migration experience, which could decrease importantly the perceived net benefits of future migration. Considering the maximum duration of a family migration spell further ensures that we are capturing this effect, as it allows us to exclude smaller "trial" or "follow-up" migration experiences. Considering the actual full duration as measured at the date of the survey provides us with a comparably good measure of the family migration experience success, regardless of whether the migration spells are completed or ongoing at the time of the educational decision. Presumably education decision makers will have further information on the success of family migration experiences, but we cannot measure this additional information so that we take the measured duration of family migration as the best possible approximation to the degree of success of family migration experiences.

Notice that the underlying reasons for failure or success of family migration experiences should be exogenous to an individual child's educational decision, except for the information provided regarding the potential benefits of education if the child migrates at some point in the future - and this is exactly the sort of 'brain gain' argument we aim to test. Note in addition that, unlike the exclusion restrictions proposed in the related literature, ${ }^{15}$ this instrument presents individual variability on its own (as opposed to household or regional variability only). Consequently, this measure appears to be a good candidate for instrumenting the probability of an individual child's future migration at the time her educational investment is being decided.

\footnotetext{
${ }^{14}$ The choice of age 12 corresponds to the age at which the decision to pursue secondary schooling is made by Cape Verdean children. Moving this threshold to age 13 or 14 does not significantly change results.

${ }^{15}$ This is the case of the historical regional rates of migration previously used by Hanson and Woodruff (2002) and McKenzie and Rapoport (2006).
} 
We nevertheless consider a number of issues that could be regarded as potential weaknesses of our identyificatij strategy and modify our specification to ensure that the instrument is not capturing any family migration effect that is correlated to educational choices. First, our baseline estimates are based on a sample of dependents whose parents were both not migrants at the time the educational decision is made. This option attempts to purge any effects of migration to the family structure (such as the absence of parents in their roles of models and guardians, as well as the requirement of older children to take on household responsibilities, be it working at home or outside). Second, success or failure of the family's migration experience may be correlated with the level of education of the migrant, which in turn could affect the educational level of the child. For this reason, it is reassuring that parental education is also included in the main regression. Finally, a successful family migration experience may generate remittances and savings that relieve credit constraints and facilitates increased educational attainment. Although self-reported credit constraints in our survey do seem to be minor for the case of Cape Verde, we evaluate the hypothesis that family migration may promote asset accumulation and therefore relieve financial constraints impeding children's educational attainment by checking how asset accumulation varies with family migration duration and family migration status. The results are presented in Tables 5 and 6. We look at asset accumulation between 1997 and 2005, as available in our survey, for one aggregate and three disaggregate asset types: land, house and car ownership. There is no statistical evidence in our case that the duration of family migration spells significantly promotes any category of asset accumulation, as displayed in Table 5. Table 6 also shows that there is no statistical evidence that having a migrant in the family promotes asset accumulation.

We believe that once we focus on dependents whose parents were both not migrants at the time of education decisions, and we control for parental education and asset ownership in the education equation, it is appropriate to assume that "family migration duration at age 12 " is only correlated with the individual schooling decision through the own probability of future migration.

Formal econometric tests support our arguments in favor of the adequacy of the instruments used in this paper. Despite all control variables included in our baseline specification (displayed in Table 7, and further discussed in the following section), "family migration duration at age 12" remains a relevant instrument. In the first stage regressions, it is individually significant at the $1 \%$ level, and an F-test on the excluded instrument rejects the hypothesis of it not having explanatory power, regardless of the critical values used: 10 from Staiger and Stock (1997)'s rule-of-thumb; 8.96 from Stock and Yogo (2005)'s more carefully derived results. Because our F-statistic is computed taking into account clustering at the household level, we deem our comparison with i.i.d. critical values as conservative. ${ }^{16}$

\footnotetext{
${ }^{16}$ Note that, to the best of our knowledge, there is not available in the econometric literature a precisely suitable critical value against which to compare our F-statistic to test for weak instruments (i.e. no critical values exist that account for clustered standard errors). For this reason, we take into account both the Staiger and Stock (1997) rule-of-thumb for a suitable instrument,
} 
As a robustness check, we choose to exploit an additional, still parsimonious, econometric specification using both "family migration duration at age 12" and "regional proportion of migrants" as exclusion restrictions. The latter variable is given by the fraction of migrants in the locality where the child resides, and is closely related to the historical regional rates of migration previously used in the related microeconometric literature, namely by Hanson and Woodruff (2002) and McKenzie and Rapoport (2006). The underlying idea is that past migration proxies well for existing networks, which strongly affect current migration at the regional level, through their effects on the net benefits of migrating.

In order for this to be a valid instrument, it is important that the reasons that first started historical migration are uncorrelated with the current motives to complete intermediate secondary education. In the case of Cape Verde, this fact seems all the more plausible since migrations in Cape Verde started centuries ago due to droughts and famines, fully exogenous to the decision of acquiring education nowadays. In any event, our specification includes several regional variables (such as island dummies, local unemployment rates, and local ratios of skilled relative to unskilled workers), which should capture any remaining general equilibrium effects on educational choices.

The first stage regressions for our alternative specification (adding "local proportion of migrants" as an instrument) are displayed in columns (3) and (4) of Table 7. Both instruments are individually significant in this set of regressions. The outcome of F-tests on the excluded instruments, however, depends on the estimation method used: the hypothesis of weak instruments is clearly rejected when robust methods, such as LIML (Limited Information Maximum Likelihood) or CUE (Continuously Updated GMM Estimator) are used, whereas this is not necessarily the case for 2SLS. Since changes in the estimated coefficients of interest are small when different estimation methods are used (namely 2SLS vs. LIML), we feel reassured that this is not a problem. ${ }^{17}$ However, taking a conservative perspective, we will adopt as baseline specification the one with the single exclusion restriction provided by "family migration duration at age 12".

Finally, the specification that includes more than one instrument provides us with a joint test for the exogeneity of both "family migration duration at age 12" and "local proportion of migrants". Exogeneity of both instruments cannot be rejected by a Sargan-Hansen test of overidentifying restrictions (robust to clustering at the household level).

and the Stock and Yogo (2005) 2SLS/LIML critical values for an instrument that meets the maximal 10\% size distortion for a $5 \%$ Wald test criterion, even though these critical values are computed assuming i.i.d. errors. An alternative possible criterion for the strength of an instrument could be not to exceed the maximal bias of $10 \%$ of the IV estimator relative to the OLS inconsistency. Critical values for this criterion are, however, only available when at least three instruments are used. Using these critical values, we can already reject the null of weak instrument, despite the fact that critical values for this criterion are decreasing in the number of instruments.

${ }^{17}$ Note that we are still comparing F-statistics adjusted for clustering at the household level, whereas the critical values used for comparison are computed assuming i.i.d. errors, which should lead to too little rejections of the null of weak instruments. 


\section{Estimation}

In order to estimate our model, and most crucially, our parameter of interest, $\alpha_{1}$, we focus first on a standard linear probability model. This has the advantage of simplicity and better-established properties and tests (e.g. for the weak instrument potential problems discussed above). In addition, as shown by Angrist (1991), the use of 2SLS to estimate binary outcomes can be justified and indeed shown to consistently estimate average treatment effects.

In a linear setting, $P\left(S_{i} \mid X_{i}\right)=S_{i}^{*}$ and $P\left(M_{i} \mid X_{i}\right)=M_{i}{ }^{*}$. Therefore, one can write $S_{i}=S_{i}^{*}+u_{1 i}$ and $M_{i}=M_{i}^{*}+u_{2 i}$. The regression model hence becomes:

$$
\begin{aligned}
& S_{i}=\alpha_{0}+\alpha_{1}{ }^{\prime} M_{i}+\alpha_{2}{ }^{\prime} X_{i}+u_{1 i} \\
& M_{i}=\beta_{0}+\beta_{1}{ }^{\prime} S_{i}+\beta_{2}{ }^{\prime} Y_{i}+u_{2 i}
\end{aligned}
$$

In this context, $\alpha_{1}$ can be simply estimated by 2 SLS on (6).

The non-linear model (4)-(5) can also be estimated consistently following Mallar (1977), taking into account the characteristics of our model (namely the dependent variables' continuity) that make it different from the model underling conventional "IV Probit" estimates. The method proposed by Mallar (1977) consists of estimating a reduced form of the index $M_{i}^{*}$ in equation (5), which we can then use as a regressor in the structural estimation of equation (4). Note that it is possible to follow this two-stage procedure given the continuity of the index function, $M_{i}^{*}$.

The model to be estimated therefore becomes:

$$
\begin{array}{llr}
S_{i}^{*}=\alpha_{0}+\alpha_{1}{ }^{\prime} M_{i}^{*}+\alpha_{2}{ }^{\prime} X_{i}+\varepsilon_{1 i} & \text { where we observe } & S_{i}=1\left(S_{i}^{*} \geq 0\right) \\
M_{i}^{*}=\pi_{0}+\pi_{1}{ }^{\prime} X_{i}+\pi_{2}{ }^{\prime} Y_{i}+u_{i} & \text { where we observe } & M_{i}=1\left(M_{i}^{*} \geq 0\right)
\end{array}
$$

The same strategy will apply to the structural estimation of equation (5). Notice that, as pointed out in Maddala (1983), we can only identify the actual parameter up to a constant. If $\left(\varepsilon_{l i}, \varepsilon_{2 i}\right)$ is distributed following a bivariate normal,

$$
N\left[\left(\begin{array}{l}
0 \\
0
\end{array}\right),\left(\begin{array}{cc}
\sigma_{\varepsilon_{1}} & \sigma_{12} \\
& \sigma_{\varepsilon_{2}}
\end{array}\right)\right],
$$

the coefficient for $M_{i}^{*}$ in (4), estimated by maximum likelihood, is a consistent estimator for

$$
\alpha_{1}{ }^{\prime} \frac{\sigma_{\varepsilon_{2}}}{\sigma_{\varepsilon_{1}}}
$$

Given its appropriateness to precisely capture the effect of a certain probability of future migration (a positive and small number limited to be between 0 and 1) on the probability of acquiring a certain level 
of education, this non-linear model is particularly relevant to interpret the discrete variable IV results, as well as to perform precise counterfactual exercises.

\section{Empirical results}

In this section, we summarize the main empirical results in this paper. In particular, we present, interpret and discuss the robustness of our 'brain gain' estimates.

\section{Preliminary evidence}

Before estimating the 'brain drain' or 'brain gain' parameters of interest discussed in the previous section, we start by examining the results in Table 8, which display simple OLS and Probit estimates of the (intermediate secondary) schooling attainment of migrants relative to non-migrants. Note that we restrict our sample to dependents aged 16-30 who never migrated before age $16 .{ }^{18}$ Focusing on those who stayed in Cape Verde until at least age 16, we can safely assume that the schooling decision was made before emigration - recall that intermediate secondary schooling should be completed before or around age 16 (allowing for repetition). This enables us to estimate the effect of the probability of future emigration on the decision to complete schooling for this subsample. ${ }^{19}$

In addition, we choose to focus on a subsample of dependents whose parents were both not migrants at the time educational decisions were made (i.e. when dependent is 12 years old, as described in the previous section). This restriction helps us to isolate the effect of the expected own probability of migration, which cannot in this way be confounded with other effects, such as those of parental migration.

Finally, note that the measure of educational attainment we use is that of a certain school grade by children in a certain age interval. This specification allows us to evaluate what the effect of migration is on attaining a given school level for children at a precisely-defined age. In our baseline model we consider attainment of an intermediate secondary school grade ( 9 years) by dependents aged 16-30 years old whose parents were both not migrants at the date of educational decisions. ${ }^{20}$ This grade is relevant because it is attained by around $40 \%$ of students and it is not compulsory, unlike primary schooling.

\footnotetext{
${ }^{18}$ Changing this threshold to age 18 did not significantly change our results. We choose to focus on dependents aged no more than 30 years old to ensure we have full information on these individuals, particularly at the household level (given the design of the survey, as detailed in Appendix A). This is also a particularly interesting interval to analyze as this corresponds to a prime working age, at which migration decisions peak.

${ }^{19}$ In addition, choosing this subsample to run our regressions is most suited to the characteristics of our survey, which, as described in Table 3, fails to capture early emigrants who left with their whole families. By focusing on individuals aged 16 to 30 years old who emigrated after age 16, we are able to minimize any selection effects that the use of our survey could imply. (This is confirmed by further detailed comparisons between our survey and census data, available from the authors upon request.)

${ }^{20}$ McKenzie and Rapoport (2006) also take completed school grades as their dependent variable, but require the use of censored-order probit models to account for problems caused by right-censoring. Because we consider a particular grade only, in addition to adopting appropriate age intervals, right-censoring for our variable of interest is unlikely.
} 
Complete secondary schooling (12 years) would also be interesting to study, but is only attained by a small fraction of individuals.

Without controlling for any other covariates, there seems to be a striking statistically significant difference between the educational attainment of migrants relative to non-migrants (nearly $+16 \mathrm{pp}$ for OLS). Following the standard in the literature on determinants of educational attainment, we consider whether the observed educational differences are still relevant after controlling for the traditional covariates: (i) individual level characteristics empirically related to performance (gender, age); (ii) household level proxies for available resources (number of children, asset ownership), as well as for the quality of family environment (highest completed parental educational level) and for perceptions of the quality of schooling (which are likely related to the expected benefits to be derived from education); and, finally, (iii) local level variables such as island, urban area, and other average local variables (such as unemployment, average per capita household expenditure and the skill to unskilled labor force ratio) that may affect local returns to schooling. After controlling for all regressors, there is a difference of a little less than $14 \mathrm{pp}$ between the educational attainment of migrants and non-migrants, which remains strongly significant. The signs of all significant coefficients are as expected and do not vary with the type of estimation.

\section{Estimating the 'brain gain' effect}

We now turn to estimating our parameter of interest, which can be interpreted as a measure of the "brain gain' effect, i.e. the impact that the own future probability of migration has on individual educational attainment. Following the identification strategy proposed and defended in the previous section, we start by using "duration of family migration at age 12" as an exclusion restriction.

We begin by simply using 2SLS to estimate equation (6). Results are displayed in Table 9, column (1). The estimated effect is substantial and statistically significant: an increase in the probability of migration by $10 \mathrm{pp}$ would increase the probability of attaining intermediate secondary schooling by $11.2 \mathrm{pp}$, ceteris paribus.

In column (2) of Table 9, we estimate the same equation (6), but now using a sample of all dependents aged between 16 and 30 years old who did not migrate before age 16 instead of only those individuals whose parents were both non-migrants when the individual was 12 years old. This allows us to evaluate the effect of having migrant parents on the educational impact of the expected own probability of migration: in this instance, as shown in column (2), evidence points to a lower impact of expected own migration, which can be understood as it being positively correlated to parental migration educational effects.

As discussed in the previous section, our initial focus on a standard linear probability model is justified by its simplicity. However, because we are interested in precisely capturing the effect of a certain probability of future migration (a positive number limited to be between 0 and 1 ) on the probability of 
acquiring a certain level of education, the non-linear Mallar (1977) model is better suited for our purposes. ${ }^{21}$ Columns (3) and (4) in Table 9 present results of the non-linear estimation of our model. Standard errors are bootstrapped. The coefficient on the latent variable for emigration is still positive and significant, suggesting the relevance of the brain gain hypothesis. The coefficients on parental absence take the same signs and statistical imprecision as in the 2SLS case. The remaining question regards the economic or quantitative significance of these effects. In the next section, we will use simulation techniques to generate counterfactual scenarios of education and emigration in order to evaluate the importance of this causal effect.

\section{Robustness check 1: instrument choice}

In our baseline specification, we explore the information content conveyed by family networks in determining an individual's likelihood to emigrate (as provided by the maximum duration of earlier migration in the household). We now turn to check the robustness of our findings by including a proxy for local migration networks as an additional determinant of an individual's probability to emigrate. In particular, we estimate our model using different techniques, including two exclusion restrictions provided to us by the "duration of family migration at age 12" and the "local proportion of migrants". (Recall that the adequacy of this procedure is discussed in Section 4.)

The results from this robustness check are displayed in Table 10. As 2SLS is less robust to the inclusion of weak instruments than LIML (Limited Information Maximum Likelihood) or CUE (Continuously Updated GMM Estimator), ${ }^{22}$ and we can only marginally reject the null hypothesis of joint weak instruments, we include estimation results for these two methods as well as for the initial 2SLS and most appropriate two-stage non-linear Mallar (1977) method.

The estimated coefficients on the probability of future emigration are remarkably stable across estimation methods: 2SLS, LIML and CUE yield similar magnitudes, pointing to an effect in the interval 8.9-10pp for a 10pp increase in the migration probability, although the LIML and CUE estimates are slightly less statistically significant than the coefficient obtained using 2SLS. Relative to the baseline specification, there is a (small) decrease in the magnitude of the estimated effect both using 2SLS and the Mallar (1977) non-linear method. Overall including an additional instrument does not greatly change results.

\footnotetext{
${ }^{21}$ In other words, we do not want to capture the effect of migrating or not $[0,1]$, but the effect of a certain probability of future migration (a number between 0 and 1). We believe that this distinction is essential in order to understand why the results using the linear probability model should not be interpreted directly.

${ }^{22}$ See Stock and Yogo (2005) for a discussion and evidence on this topic.
} 


\section{Robustness check 2: sample choice}

One may think that our estimates are capturing a local effect on a particular subgroup of individuals. In particular, one could conjecture that the 'brain gain' effect should be concentrated on those who actually end up migrating at some point in the future.

In order to check this hypothesis we consider the following latent variable for the decision of obtaining education for individuals who never migrated:

$$
S_{i}^{*}=\alpha_{0}+\alpha_{1} \operatorname{Pr}\left(M_{i}=1\right)+\alpha_{2}{ }^{\prime} X_{i}+\varepsilon_{s i} \quad \text { where we observe } \quad S_{i}=1\left(S_{i}^{*} \geq 0\right)
$$

According to (10), child $i$ 's educational attainment $\left(S_{i}\right)$ depends on $\operatorname{Pr}\left(M_{i}=1\right)$, the probability of own future migration.

In order to identify our parameter of interest $\left(\alpha_{1}\right)$, the first step in our empirical procedure is the estimation of the probability to emigrate for dependents aged 16 to 30 who never migrated. We then proceed to a second step in which we use characteristics of individuals at age 12 (using our full history of residents and migrants' lives and associated characteristics) to predict their probability of emigration at that age. In a third and final step, this predicted probability of future emigration evaluated at age 12 is used as an independent variable. To account for the estimation procedure of the probability of future migration, standard errors are bootstrapped.

The results obtained from this procedure are summarized in Table 11. We find that the effect of the own probability of future migration on those who never migrated seems to be actually larger than for comparable individuals who migrated from age 16. Indeed, the estimated coefficients displayed in Table 11 are larger than those obtained in any of the specifications we considered before. For the case of 2SLS, the interpretation of the coefficient is very clear: an increase in the probability of own future migration of 10pp would increase the probability of attaining intermediate secondary schooling by 9 to $12.5 \mathrm{pp}$, ceteris paribus.

\section{Counterfactual results: educational responses to migration barriers}

The objective of this section is to illustrate the economic significance of the 'brain gain' estimates we obtained. In particular, we derive the quantitative implications on educational attainment of changing barriers to migration (e.g. caused by tightened immigration policies in destination countries) by using our estimation of the non-linear simultaneous-equation Mallar (1977) model. Unlike existing studies, which assume the educational attainment of current and return emigrants would have been the same had they not emigrated, our model allows us to consider the impact of migration policy shocks on both education and migration decisions. 
Using this framework, we start by examining the impact of changes in migration barriers on emigration and, as a consequence, on the educational attainment of individuals aged 16-30 who never resided away from Cape Verde until age 16 (following the estimation methodology adopted in the previous section). Our simultaneous equation model allows us to evaluate the differential impact on educational attainment for those who choose to emigrate and for those who do not.

We then turn to analyzing the impact of the same shock on the emigration and educational decisions of all Cape Verdean born individuals aged 16 to 30. This includes individuals who emigrated before age 16, who will potentially have obtained (further) education after migration. For this reason, in this exercise we complement our survey with data from the censuses of the main host countries.

\section{Changes in migration barriers for individuals who resided in Cape Verde at least until age 16}

We begin by creating a counterfactual shock decreasing emigration prospects in our empirical model. ${ }^{23}$ It basically consists of exogenously reducing the constant term in the migration equation (5) by an amount $\delta . \sigma_{2}$, where $\delta$ is an arbitrary positive value and $\sigma_{2}$ is the variance of the error term in the reduced form of the migration equation. ${ }^{24}$ This shock may be interpreted as an increase in emigration barriers that do not directly affect the incentives to invest in education - for example, a tightening in immigration policies of receiving countries.

As detailed in Appendix C, given our parameter estimates and the individual values of $X_{i}$ and $Y_{i}$ in our sample, we can simulate individual decisions of educational attainment and migration and, given those decisions, calculate the educational attainment of migrants and of non-migrants, as displayed in column (2) of Table 12. Indeed, columns (1)-(2) in Table 12 show that our procedure approximates well actual migration rates and educational attainment of both migrants and non-migrants.

For a given counterfactual shock, we can re-compute relevant parameters, and again simulate individual migration and education decisions. Columns (3)-(6) in Table 12 describe what happens when barriers to migration gradually increase. First, as expected, a gradual increase in migration barriers implies a gradual decrease in the probability of emigration. Second, as a consequence, educational attainment (especially of non-migrants) is strikingly affected by the lower probability of migration: when emigration falls by $11 \mathrm{pp}$, the probability of attaining intermediate secondary education decreases by $16 \mathrm{pp}$ for non-migrants (implying an elasticity of 0.32), whereas the reduction for migrants is smaller but still sizable (nearly $7 \mathrm{pp}$, implying an elasticity of 0.10 ). ${ }^{25}$ Note that the educational costs of closing migration possibilities seem to be non-linear (indeed non-monotonically increasing): instead of cutting

\footnotetext{
${ }^{23}$ Appendix $\mathrm{C}$ presents in detail the derivations underlying our methodology.

${ }^{24}$ Notice that due to the endogeneity of migration and educational attainment, a decrease in the constant term of (5) would affect the reduced form of both the migration and the educational attainment equations.

${ }^{25}$ This asymmetric behavior is due to the positive correlation between the reduced form error terms $\left(u_{1 i}, u_{2 i}\right)$. In the counterfactual world, when it becomes harder to emigrate, only those who have very high random draws, $u_{2 i}$, will eventually emigrate. Those individuals also present high $u_{l i}$, decreasing the effect of the overall reduction on $S^{*}$ due to the fall in $M^{*}$.
} 
the stock of migrants from $13 \%$ to $2 \%$ as in the example above, it is much less costly in terms of educational attainment to bring the stock of emigrants down from say 13\% to 9\% of Cape Verdean nationals (which implies an elasticity of 0.19 for non-migrants, and 0.07 for migrants). Overall, these counterfactual results are strongly supportive of the hypothesis of 'brain gain' as opposed to 'brain drain'. ${ }^{26}$

\section{Changes in migration barriers for all individuals who were born in Cape Verde}

The counterfactual scenarios just described may be over-estimating the educational costs of restricting migration. Indeed, changes in migration barriers may prompt those who emigrated before age 16 to return to Cape Verde, and these individuals may be more likely to have attained intermediate secondary schooling than the corresponding person in Cape Verde or an emigrant departing at an older age. To investigate this possibility, we now propose a way to account for the number and characteristics of individuals who migrated before age 16 by combining information from census data of the destination countries.

As detailed in Appendix C, we propose to re-weight the original survey individual observations in order to account for the missing individuals who migrated before age $16 .{ }^{27}$ The idea is to use weights in order to increase the importance of migrants who departed after age 16 in our sample and whose characteristics match the characteristics of all migrants.

Table 13 shows the reweighted results. Compared to Table 12, both non-migrants and migrants display slightly increased educational performance. This happens because our counterfactual scenarios now indirectly include some of the migrants departing before age 16 , who are better educated than those who are leaving later in life. Nevertheless, it is clear that educational attainment still falls visibly when emigration decreases: a 12pp decrease in the probability of migrating is associated with a fall of $12 \mathrm{pp}$ in the educational attainment for non-migrants (implying an elasticity of 0.26 ), and a drop of $3 \mathrm{pp}$ in the educational attainment for migrants (implying an elasticity of 0.06). Once more, we observe that the educational costs of closing migration possibilities seem to be non-linear: it is much less costly in terms of educational attainment to bring the stock of emigrants down from $17 \%$ to $13 \%$ of Cape Verdean nationals (implying an elasticity of 0.17 for non-migrants, and 0.05 for migrants), than from $17 \%$ to $3 \%$ (implying an elasticity of 0.29 for non-migrants, and 0.08 for migrants). This evidence is again suggestive of the importance of the 'brain gain' mechanism, now even after we account for the

\footnotetext{
${ }^{26}$ Note that additional human capital gains from emigration are created by return migration. We abstract from this channel in the present exercise as return migration does not seem quantitatively important for our specific counterfactual exercise: indeed, only $4 \%$ of all emigrants aged 16 to 30 years old report to have returned. This is consistent with the odds of temporary migration increasing with the age of migration (Lacuesta, 2006). A more adequate treatment of the 'brain gain' from return migration can be found in Batista et al. (2007).

${ }^{27}$ Recall that early emigrants (before age 16) are not well described in our survey, as they mostly left with their whole families.
} 
educational upgrade by early migrants who may return when migration policies are made more restrictive.

A caveat to the real world validity of these counterfactual simulations has to do with the fact that most developed countries are adopting immigration policies that are selective relative to the educational attainment of potential immigrants. This is not taken into account in our simple counterfactual exercise and raises important questions: How quantitatively relevant is the fact that many countries are only willing to admit skilled immigrants in detriment of those unskilled? In other words, how strong are the effects of distortionary immigration policies on educational attainment in the sending country? This is an essential direction for future research that is left unanswered by our analysis.

\section{Why does the own future probability of migration matter for educational decisions?}

According to our empirical results, there is a sizable positive effect of the own future probability of emigration on educational attainment. This finding raises further questions. In particular, one would like to understand the mechanisms underlying this effect.

The original 'brain gain' theory hinged on the traditional selection arguments proposed by Borjas (1987) and emphasized that the option of emigrating to a country where returns to schooling are higher should increase an individual's incentive to acquire education. Our evidence points however to returns to education in the United States never overcoming returns to education in Cape Verde. ${ }^{30}$ Why should then the possibility of own future migration create incentives for acquiring education at home?

Hatton and Williamson (2001) observe that emigration out of African countries seems to be significantly determined by cross-country real wage differentials. In the likely event that wage differentials between Cape Verde and the destination countries of its emigrants have not been competed away ${ }^{31}$ - as assumed by the standard Roy model selection arguments used by Borjas (1987) - it may then be more appropriate to consider the alternative model of Jasso and Rosenzweig (2005), as proposed by Akee (2009). This model, which may be thought of as nested within the Roy model, takes the first (instead of the second) moments of the income distribution across countries (i.e. wage differentials) as determining incentives for the most educated individuals to emigrate. In this context, skilled individuals decide to emigrate despite the lower relative returns to education abroad because of the sizable absolute differences in wages. ${ }^{33}$

\footnotetext{
${ }^{30}$ These results and related discussion are available from the authors upon request.

${ }^{31}$ Batista (2008) discusses other instances in which this is the case even within more closely integrated economies, namely within the European Union.

${ }^{33}$ Rosenzweig (2007), Belot and Hatton (2008) and Hanson and Grogger (2008) all present evidence supportive of this absolute wage differentials hypothesis - the first for Asian students in the US, and the latter two for immigrants in OECD countries.
} 
Table 14 shows that indeed there are substantial differences between annual wages in Cape Verde and the US. ${ }^{34}$ The average 25-50 year old male, can earn around 12,000 additional international dollars after migrating to the US. This difference is significantly wider (21,000 additional international dollars) if we do not adjust for purchasing power differences, which makes sense for those who are able to save and remit US earnings to Cape Verde. If we take into account educational attainment, we observe that the US-Cape Verde wage differential for those who complete intermediate secondary schooling ( 9 grades) is only 540 international dollars, or $8 \%$ of the average unskilled annual wage in Cape Verde. This differential between educated and non-educated workers is much higher when we do not take PPP into consideration: it amounts to 4582 international dollars, or $232 \%$ of the average unskilled annual wage in Cape Verde.

This evidence is supportive of the hypothesis that absolute wage differentials determine positive emigrant selection in Cape Verde (as opposed to relative returns to education). This seems to be especially the case when there is an intention to save and return to the origin country, or sizable remittances are sent back home. For individuals who emigrate with their whole family and who do not plan to return to the origin country, it is, however, not obvious that it compensates to invest in further education based on absolute real wage differentials alone.

We argue that, in addition to the observed wage differentials, the incentive to acquire further education for individuals who plan to permanently emigrate in the future may also arise from decreased migration costs due to education (as may be true of language barriers or skill-selective immigration policies in most developed destination countries, for example). In this instance, individuals would be interested in acquiring more education to achieve a higher probability of emigration in the future, in line with the predictions of Chiquiar and Hanson (2005) for the Mexican case. This argument is similar to that of absolute wage differentials, but further explores the implications of nominal costs of migration, which may depend on individual levels of education.

Preliminary evidence seems to be supportive of this argument: immigration policy in the US has traditionally been more skill-selective than in Portugal, which is consistent with the observed positive educational selection of emigrants being much stronger to the US than to Portugal. Selection patterns seem to also follow linguistic distances: evidence points to selection patterns of emigration to France being very similar to those of emigration to the US, whereas emigration to Spain closely resembles emigration to Portugal, ${ }^{35}$ which is in line with the Portuguese language (spoken in Cape Verde) being

\footnotetext{
${ }^{34}$ The Portuguese census does not provide information on wages, and in other sources there are too few Cape Verdean in the sample. We compare information on wages earned by Cape Verdean in the US (from IPUMS, Ruggles et al. 2004) and in Cape Verde (from INE 2004).

${ }^{35}$ Considering immigrants in the French census coming from non-French speaking African countries, we observe that their selection pattern is similar to that of Cape Verdean immigrants in the United States. On the contrary, the Spanish census points to immigrant selection being very similar to that coming from the Portuguese census.
} 
very similar to Spanish, but not to French and English. Immigration policies and linguistic distance may indeed be further motives than simple wage gaps for migrants to acquire additional education before leaving the origin country.

\section{Concluding remarks}

This paper contributes in various ways to the important but still scarce literature on the effects of emigration in origin countries. It departs from the essential premise that educational choices may depend on emigration options. This assertion has important implications. First, it demands an explicit test for the effect of the prospect of own future emigration on educational attainment - the original 'brain gain' hypothesis. Our empirical strategy uses full histories of migrants provided by our tailored microdata survey, allowing us to directly test this hypothesis unlike existing studies. Second, it suggests the need to correct for educational upgrading after emigration. This correction addresses an important shortcoming in past work assuming that the educational attainment of current and return emigrants would have been the same had they not emigrated. In our counterfactual simulations of changes in migration barriers, we take this consideration into account by combining our survey data with information from censuses of the main destination countries, while using a model simultaneously determining migration and educational decisions.

Overall, our results point to 'brain drain' not being as serious a problem as traditionally thought. Indeed, this paper finds that massive emigration from Cape Verde seems to have significantly encouraged the accumulation of human capital in the country. Our estimates suggest that an increase in the probability of own future migration by 10pp increases the average probability of completing intermediate secondary schooling by around 11.2pp.

The evidence obtained in this study should lead policymakers in both developing and developed countries not to focus their attention in restricting migration flows of educated individuals. Not only are destination countries likely to benefit from the inflow of these skilled immigrants, as is relatively undisputed, but these flows may also be beneficial for origin countries as Cape Verde. Indeed, while further studies on other source countries of educated migration are required to make a general argument, for this case at least, keeping the doors of rich countries open to educated migration may be regarded as a form of "efficient aid".

\section{References}

Akee, Randall (2009). "Who's Leaving? Deciphering Immigrant Self-Selection From a Developing Country", Economic Development and Cultural Change.

Angrist, Joshua (1991). "Instrumental Variables Estimation of Average Treatment Effects in Econometrics and Epidemiology", NBER Technical Working Paper 115. 
Barro, Robert J., and Jong-Wha Lee (2001). "International Data on Educational Attainment: Updates and Implications", Oxford Economic Papers, 53: 541-563.

Batista, Catia (2008). "Why Doesn't Labor Flow from Poor to Rich Countries? Micro Evidence from the European Integration Experience", Oxford Working Paper 402.

Batista, Catia, Aitor Lacuesta, and Pedro Vicente (2007). "Brain Drain or Brain Gain? Micro Evidence from an African Success Story", IZA Discussion Paper 3035.

Beine, Michel, Frederic Docquier, and Hillel Rapoport (2008). "Brain drain and LDCs' growth: winners and losers", Economic Journal, 118:631-652.

Beine, Michel, Cecily Defoort, and Frederic Docquier (2007). "A Panel Data Analysis of The Brain Gain”, Working Paper, Université Catholique de Louvain.

Belot, Michele, and Timothy Hatton (2008). "Immigrant Selection in the OECD", CEPR Working Paper 6675.

Bhagwati, J., and K. Hamada (1974). "The brain drain, international integration of markets for professionals and unemployment: a theoretical analysis", Journal of Development Economics, 1: 19-42.

Borjas, George (1987). "Self-Selection and the Earnings of Immigrants", American Economic Review, 77(4): 531-53.

Carrington, William, and Enrica Detragiache (1998). "How Big is the Brain Drain?", IMF Working Paper 98/102.

Chiquiar, Daniel, and Gary Hanson (2005). "International Migration, Self-Selection, and the Distribution of Wages: Evidence from Mexico and the United States", Journal of Political Economy, 113(2): 239-281.

Chiswick, Barry, and Timothy Hatton (2003). "International Migration and the Integration of Labor Markets", in Michael Bordo, Alan Taylor and Jeffrey Williamson (eds.), Globalization in Historical Perspective. Cambridge, MA: NBER.

Collier, Paul, Anke Hoeffler, and Catherine Pattillo (2004). "African Exodus, Brain Drain and Capital Flight", Journal of African Economies, 13 (AERC Supp.2): ii15-ii54.

Docquier, Frédéric, and Abdeslam Marfouk (2006). "International Migration by Education Attainment, 1990-2000", in Ozden and Schiff (eds.), International Migration, Brain Drain and Remittances, pp. 151-99. New York, NY: Palgrave Macmillan.

Faini, Riccardo (2006). "Remittances and the Brain Drain”, IZA Discussion Paper 2155.

Grogger, Jeffrey, and Gordon Hanson (2008). "Income Maximization and the Selection and Sorting of International Migrants", NBER Working Paper 13821.

Gruber, Herbert, and Anthony Scott (1966). "The International Flow of Human Capital", American Economic Review, 56: 268-274.

Hanson, Gordon, and Christopher Woodruff (2003). "Emigration and Educational Attainment in Mexico", Working Paper, UCSD.

Heston, Alan, Robert Summers and Bettina Aten (2006). Penn World Table Version 6.2, Center for International Comparisons of Production, Income and Prices at the University of Pennsylvania.

Hatton, Timothy, and Jeffrey Williamson (2001). "Demographic and Economic Pressure Out of Africa", NBER Working Paper 8124.

Instituto Nacional de Estatistica (2002). Recenseamento Geral da População e da Habitação. Cidade da Praia, Cabo Verde: INE.

Instituto Nacional de Estatistica (2004). Inquérito às Despesas e Receitas Familiares. Cidade da Praia, Cabo Verde: INE. 
Jasso, Guillermina, and Mark Rosenzweig (2005). "Selection Criteria and the Skill Composition of Immigrants: A Comparative Analysis of Australian and US Employment Immigration", Working Paper.

Lacuesta, Aitor (2006). "Emigration and Human Capital: Who Leaves, Who Comes Back and What Difference Does it Make?", Working Paper Bank of Spain 0620.

Maddala, G. S. (1983). Limited-dependent and qualitative variables in econometrics. Cambridge University Press.

Mallar, C. D. (1977). "The estimation of Simultaneous Probability Models", Econometrica, 45(7): 171722.

McKenzie, David, and Hillel Rapoport (2006). "Can migration reduce educational attainment?", World Bank Policy Research Paper 3952.

Mountford, Andrew (1997). "Can a brain drain be good for growth in the source economy?", Journal of Development Economics, 53: 287-303.

Ozden, Caglar, and Maurice Schiff (Eds.) (2006). International Migration, Remittances and the Brain Drain. New York, NY: Palgrave MacMillan.

Rosenzweig, Mark (2007). "Higher education and international migration in Asia: brain circulation", Working Paper, Yale University.

Ruggles S., M. Sobek, T. Alexander, C. Fitch, R. Goeken, P. Kelly Hall, M. King, and C. Ronnander (2004). Integrated Public Use Microdata Series: Version 3.0. Minneapolis, MN: Minnesota Population Center.

Staiger, D., and J. Stock (1997). "Instrumental variables regression with weak instruments", Econometrica, 65(3): 557-86.

Stark, O., C. Helmenstein, and A. Prskawetz (1997). "A brain gain with a brain drain”, Economic Letters, 55: 227-234.

Stark, O., C. Helmenstein, and A. Prskawetz (1998). "Human capital formation, human capital depletion, and migration: a blessing or a "curse", Economic Letters, 60: 363-367.

Stock, James and Motohiro Yogo (2005). “Testing for Weak Instruments in Linear IV Regression”, in Identification and Inference for Econometric Models: Essays in Honor of Thomas Rothenberg, ed. D. Andrews and J. Stock, 80-108. Cambridge University Press.

Vidal, Jean Pierre (1998). "The effect of emigration in human capital formation", Journal of Population Economics, 11:589-600.

World Bank (2006a), Global Economic Prospects. Economic Implications of Remittances and Migration. World Bank: Washington, DC.

World Bank (2006b). World Development Indicators, September 2006. World Bank: Washington, DC.

\section{Appendix A: Household survey}

The tailored data collection consisted of survey (face-to-face) interviews conducted by teams of local interviewers and one of the authors. The interviews were conducted from December 2005 to March 2006. We were responsible for the recruitment and training of the local teams - made sure that each interviewer had at least a total of 18 hours of training in groups of 2-3 individuals. Training included lectures on the content/objectives of the survey; answering the questionnaire; and piloting (at least once per interviewer). 
The survey questionnaire was submitted to 1066 households (997 complete interviews) in 30 (or 5\%) of the 561 census areas of Cape Verde. It was composed of two modules: one on perceived quality/corruption of public services; and the other on migration characteristics of the household. The English translation for the full questionnaire is available at http://www.csae.ox.ac.uk/resprogs/corruption/cv/questcveng.pdf.

The sampling process was such that sampled census areas were chosen randomly weighting by the number of households, and households within a census area were chosen randomly using standard techniques ( $\mathrm{n}^{\text {th }}$ house, with second visits tried in the same day). The requirement condition for a household to be interviewed was family residence in the country anytime in 1985-2006. The requirement condition for a respondent within a household to be interviewed was to be aged 30 or more years old.

There were two imperfections to the random sampling of households in the survey. One was differences in attempted interviews in the different census areas, and the other was the fact that we had nonrespondents. We use weighted data to account for these problems (although differences to unweighted data are negligible throughout) for which data collected from non-respondents are exploited (gender, approximate age, approximate schooling, and approximate income).

Additional details on the fieldwork and survey can be found at http://www.csae.ox.ac.uk/resprogs/corruption/cv/cv.htm.

\section{Appendix B: Classification of educational attainment}

Comparing educational attainment from different sources is often difficult because of variations in classification. In all data sets, there are questions regarding complete levels of education. However, the disaggregation level is higher in some sources, which may make it difficult to draw comparisons with sources adopting lower disaggregation levels. For instance, Docquier and Marfouk (2006) identify the selection of migrants in three educational groups: less than 9 years of schooling (low education), 9-12 years of schooling (medium) and over 13 (high). The Portuguese and the US census allow grouping migrants in such way since the group of people who have some college without having finished the degree (13-14 years of schooling) is identified separately. However, in the Cape Verdean census and in our survey, individuals must be classified either at the pre-university level (12 years of schooling) or at the completed university level (at least 15 grades of schooling). Therefore, the pre-university level also includes people who did not finish their university degree.

As is detailed in Table A1 below, we group individuals in 4 groups: less than intermediate secondary (less than 9 years of schooling), completed intermediate secondary (between 9 and 11 years of schooling), completed secondary (between 12 and 14 years of schooling) and completed university degree (15 years of schooling or more). In comparison with Docquier and Marfouk (2006), both 
classifications have the same low education group (less than 9 years). However, adding our second and third groups encompasses more than their intermediate group since our third group includes individuals who did not finish their university degree. For the same reason, our top group of education should be smaller than their high skilled.

Table A1 - Comparison of educational classifications in Portugal (census), United States (census) and Cape Verde (survey)

\begin{tabular}{|c|c|c|c|c|}
\hline & \multicolumn{2}{|c|}{ Portugal 2001} & $\begin{array}{l}\text { United States } 2000 \\
\quad \text { (Completed) }\end{array}$ & Cape Verde 2006 (Completed) \\
\hline \multirow{11}{*}{$\begin{array}{l}\text { LESS THAN } \\
\text { INTERMEDIATE } \\
\text { SECONDARY }\end{array}$} & & & Not applicable and no school & \\
\hline & & No schooling & $(0,1)$ & Illiterate (1) \\
\hline & & Preschool & & Pre-primary (2) \\
\hline & \multirow{3}{*}{$\begin{array}{l}1^{\circ} \text { Cycle }=4 \text { years } \\
\text { of schooling }\end{array}$} & Attending & 1-4 grades (4) & Attending Primary (3) \\
\hline & & Incomplete & & \\
\hline & & Complete & & \\
\hline & \multirow{3}{*}{$\begin{array}{l}2^{\circ} \text { Cycle }=6 \text { years } \\
\text { of schooling }\end{array}$} & Attending & & \\
\hline & & Incomplete & & \\
\hline & & Complete & & \\
\hline & \multirow{2}{*}{$\begin{array}{l}3^{\circ} \text { Cycle }=9 \text { years } \\
\text { of schooling }\end{array}$} & Attending & & Complete primary (4) \\
\hline & & Incomplete & $5-8$ grades $(5)$ & From 6 to 9 grades (5) \\
\hline \multirow{4}{*}{$\begin{array}{l}\text { COMPLETED } \\
\text { INTERMEDIATE } \\
\text { SECONDARY }\end{array}$} & \multirow{4}{*}{$\begin{array}{l}\text { Secondary }=12 \\
\text { years of schooling }\end{array}$} & Complete & 9 grades $(6)$ & Secondary (6) \\
\hline & & & 10 grades $(7)$ & \\
\hline & & Attending & 11 grades $(8)$ & \\
\hline & & Incomplete & 12 grades (no diploma) (9) & \\
\hline \multirow{9}{*}{$\begin{array}{l}\text { COMPLETED } \\
\text { SECONDARY }\end{array}$} & \multirow{7}{*}{$\begin{array}{l}\text { Medium }=14 \\
\text { years of schooling } \\
\text { Baccalaureate }=15 \\
\text { years of schooling }\end{array}$} & Complete & High school graduate (10) & Pre-University (7) \\
\hline & & & Some College no degree (11) & \\
\hline & & & $\begin{array}{l}\text { Associate degree/occupational } \\
\text { (12) }\end{array}$ & \\
\hline & & Incomplete & & \\
\hline & & Complete & Professional degree (16) & \\
\hline & & Attending & & \\
\hline & & Incomplete & & \\
\hline & \multirow{2}{*}{$\begin{array}{l}\text { Licentiate }=17 \\
\text { years of schooling }\end{array}$} & Attending & & \\
\hline & & Incomplete & & \\
\hline COMPLETED & Baccalaureate & Complete & Bachelor (14) & Bachelor (8) \\
\hline \multirow[t]{7}{*}{ UNIVERSITY } & Licentiate & Complete & & University (9) \\
\hline & Master $>=17$ years & Attending & & \\
\hline & of schooling & Incomplete & & \\
\hline & \multirow{4}{*}{$\begin{array}{l}\text { Doctorate }>=20 \\
\text { years of schooling }\end{array}$} & Complete & Master (15) & \\
\hline & & Attending & & \\
\hline & & Incomplete & & \\
\hline & & Complete & Doctorate (17) & \\
\hline
\end{tabular}




\section{Appendix C: Counterfactual exercise}

The structural system given by (4)-(5) can be expressed in reduced form as: ${ }^{37}$

$$
\begin{array}{lll}
S_{i}^{*}=\frac{\lambda_{0}}{\sigma_{1}}+\frac{\lambda_{1}{ }^{\prime}}{\sigma_{1}} X_{i}+\frac{\lambda_{2}{ }^{\prime}}{\sigma_{1}} Y_{i}+\frac{u_{1 i}}{\sigma_{1}} & \text { where we observe } & S_{i}=1\left(S_{i}^{*} \geq 0\right) \\
M_{i}^{*}=\frac{\pi_{0}}{\sigma_{2}}+\frac{\pi_{1}{ }^{\prime}}{\sigma_{2}} X_{i}+\frac{\pi_{2}{ }^{\prime}}{\sigma_{2}} Y_{i}+\frac{u_{2 i}}{\sigma_{2}} & \text { where we observe } & M_{i}=1\left(M_{i}^{*} \geq 0\right)
\end{array}
$$

where $\sigma_{1}$ and $\sigma_{2}$ are the standard deviations of $u_{l}$ and $u_{2}$, respectively.

Given that the error terms $\left(\varepsilon_{l i}, \varepsilon_{2 i}\right)$ in the structural model follow a bivariate normal distribution with correlation $\rho$, i.e. $\left(\varepsilon_{l i}, \varepsilon_{2 i}\right) \sim N\left[\left(\begin{array}{l}0 \\ 0\end{array}\right),\left(\begin{array}{cc}1 & \rho \\ & 1\end{array}\right)\right]$, the error terms in the reduced form $\left(\frac{u_{1}}{\sigma_{1}}, \frac{u_{2}}{\sigma_{2}}\right)$ also follow a bivariate normal distribution: ${ }^{38}$

$$
\left(\frac{u_{1}}{\sigma_{1}}, \frac{u_{2}}{\sigma_{2}}\right) \sim N\left[\left(\begin{array}{l}
0 \\
0
\end{array}\right),\left(1 \quad\left(\frac{1}{\sigma_{1} \sigma_{2}}\right)\left(\frac{1}{1-\alpha_{1} \beta_{1}}\right)^{2}\left(\beta_{1}+\alpha_{1}+\rho\left(1+\alpha_{1} \beta_{1}\right)\right)\right)\right]
$$

In order to predict individual decisions on migration and educational attainment, one needs to have estimates for the corresponding latent variables, $M^{*}$ and $S^{*}$. To obtain these estimates, we start by estimating (11) and (12). In addition, we need to predict the error terms $\left(\mathrm{u}_{1} / \sigma_{1}, \mathrm{u}_{2} / \sigma_{2}\right)$ for each individual. To account for the correlation between these error terms, we must have estimates for structural parameters $\alpha_{1}$ and $\beta_{1}$, and for the correlation between structural error terms $\rho .^{39}$

Using the two step method of Mallar (1977), we estimate $\alpha_{1}$ and $\beta_{1} \cdot{ }^{40}$ As this estimation procedure does not provide a direct estimate for the correlation between the two structural errors, we calibrate a covariance for $\left(\varepsilon_{1 i}, \varepsilon_{2 i}\right)$ to match the educational attainment of migrants and non-migrants. We grid over different values in the interval [-1,1], and take $\operatorname{cov}\left(\varepsilon_{1 i}, \varepsilon_{2 i}\right)=\rho=-0.75$. With the values for these parameters in hand, we can now compute $\sigma_{1}$ and $\sigma_{2}$.

\footnotetext{
${ }^{37}$ Recall that a probit model estimates the coefficients up to the standard deviation of the error term.

${ }^{38}$ Notice that $u_{1}=\frac{1}{1-\alpha_{1} \beta_{1}}\left(\varepsilon_{1}+\alpha_{1} \varepsilon_{2}\right)$ and $u_{2}=\frac{1}{1-\alpha_{1} \beta_{1}}\left(\varepsilon_{2}+\beta_{1} \varepsilon_{1}\right)$.

${ }^{39}$ Note that $\sigma_{1}^{2}=\left(\frac{1}{1-\alpha_{1} \beta_{1}}\right)^{2}\left(1+\alpha_{1}^{2}+2 \alpha_{1} \rho\right)$ and $\sigma_{2}^{2}=\left(\frac{1}{1-\alpha_{1} \beta_{1}}\right)^{2}\left(1+\beta_{1}^{2}+2 \beta_{1} \rho\right)$.

${ }^{40}$ Our exclusion restrictions are family migration duration at age 12 for the migration equation; and number of children in the household, regional fraction of educated individuals, and quality of educational system as perceived by household's head for the educational attainment regression.
} 
Given our parameter estimates and the individual values of $X_{i}$ and $Y_{i}$ in our sample, we are now ready to simulate individual decisions in 1000 different economies. The way to do it is to draw 1000 pairs of $\left(\mathrm{u}_{1 i} / \sigma_{1}, \mathrm{u}_{2 i} / \sigma_{2}\right)$ per individual from the bivariate normal distribution described by (13). For each draw we estimate an individual decision of educational attainment and migration and, given those decisions, we calculate the educational attainment of migrants and of non-migrants.

One way of creating a counterfactual shock to decrease emigration prospects in our empirical model is by exogenously reducing the constant term in the structural migration equation (5) by a certain amount: $\delta . \sigma_{2}$, where $\delta$ is an arbitrary positive value and $\sigma_{2}$ is the variance of the error term in the reduced form of the migration equation. ${ }^{41}$ Therefore, $\beta_{0}$ becomes $\beta_{0}{ }^{*}=\beta_{0^{-}} \delta \sigma_{2}<\beta_{0}$. This reduction may be interpreted as an increase in emigration barriers that do not directly affect the incentives to invest in education - for example, a tightening in immigration policies of receiving countries. The change in the constant term of the reduced form of the migration equation (12) is $\delta$, and the change in the constant term of the reduced form of the educational attainment equation (11) is a linear function of $\delta$, depending on parameters $\alpha_{1}, \sigma_{1}$ and $\sigma_{2}: \frac{\pi_{0}^{*}}{\sigma_{2}}=\frac{\pi_{0}}{\sigma_{2}}-\delta$ and $\frac{\lambda_{0}^{*}}{\sigma_{1}}=\frac{\lambda_{0}}{\sigma_{1}}-\delta \frac{\sigma_{2}}{\sigma_{1}} \alpha_{1}^{\prime}$

Taking into account this change in the constant terms of reduced form equations (11) and (12), we can simply re-predict individual decisions of educational attainment and migration for 1000 simulated economies and re-calculate educational attainment for migrants and for non-migrants.

We propose to re-weight the original survey individual observations in order to account for the missing individuals who migrated before age 16. Assuming that there is a set of observable characteristics $X$ (such as gender and a quartic on age) determining educational attainment in the same way for emigrants who departed before and after age 16, we would just need to use individual weights so as to increase the importance of migrants who departed after age 16 in our sample and whose characteristics match the characteristics of all migrants. ${ }^{42}$

To see how this re-weighting procedure is implemented, consider the distribution of characteristics of all migrants, $f(x \mid$ mig $)$, where mig denotes the realized decision to migrate and $x$ is the realization of $X$. Using Bayes rule, one can write:

$$
f(x \mid \text { mig })=\theta(x) f(x \mid \text { mig }>16) \quad \text { where } \quad \theta(x) \equiv \frac{1}{P(\text { mig }>16 \mid \text { mig }, X)} P(\text { mig }>16 \mid \text { mig })
$$

\footnotetext{
${ }^{41}$ Notice that due to the endogeneity of migration and educational attainment, a decrease in the constant term of (5) would affect the reduced form of both the migration and the educational attainment equations. In order to see this, just substitute equation (5) in (4) and vice versa.

${ }^{42}$ Reweighting data from the origin country instead of imputing the educational attainment observed in the destination country has the advantage that we do not need to consider directly educational upgrading from entering in a different educational system. One shortcoming might be that we miss some unobserved differences between migrants who are early (before age 16) and late migrants.
} 
This expression connects the distribution of characteristics $x$ for individuals who migrated after age 16, $f(x \mid$ mig $>16)$, available from our survey, to the distribution of characteristics of all migrants, $f(x \mid m i g)$ available from census data in the destination countries, and which we would like to reproduce in a re-weighted sample. The link between these two distributions is given by the reweighting function $\theta(x)$ : this is the ratio between the overall probability of migrating after age 16 (which can be computed from the information on all migrants available from the international censuses), $P(m i g>16 \mid \mathrm{mig})$, and the probability of migrating after age 16 for an individual with certain characteristics $X$ (which can be computed by estimating probit regression of the probability of migrating after age 16 depending on to gender and a quartic on age, again using information from the international censuses $), P($ mig $>16 \mid \mathrm{mig}, X){ }^{43}$

43 We use information from the US census 2001 (from Ruggles et al. 2004) to estimate $P(m i g>16 \mid m i g)$ and $P(m i g>16 \mid m i g, X)$. We only have information about the age of entry of migrants from Cape Verde to Portugal from the Portuguese Labor Force Survey. However, we do not have enough observations to perform this same estimation (recall that we are restricting the sample to migrants from Cape Verde between 16 and 30 years old). Because age of entry is not a variable in the Portuguese census, we must assume that the timing of migration is the same in both destination countries. This assumption seems appropriate according to tabulations in our survey for age of entry according to destination. 


\section{Figures}

Figure 1: Remittances. FDI and Aid in Cape Verde.

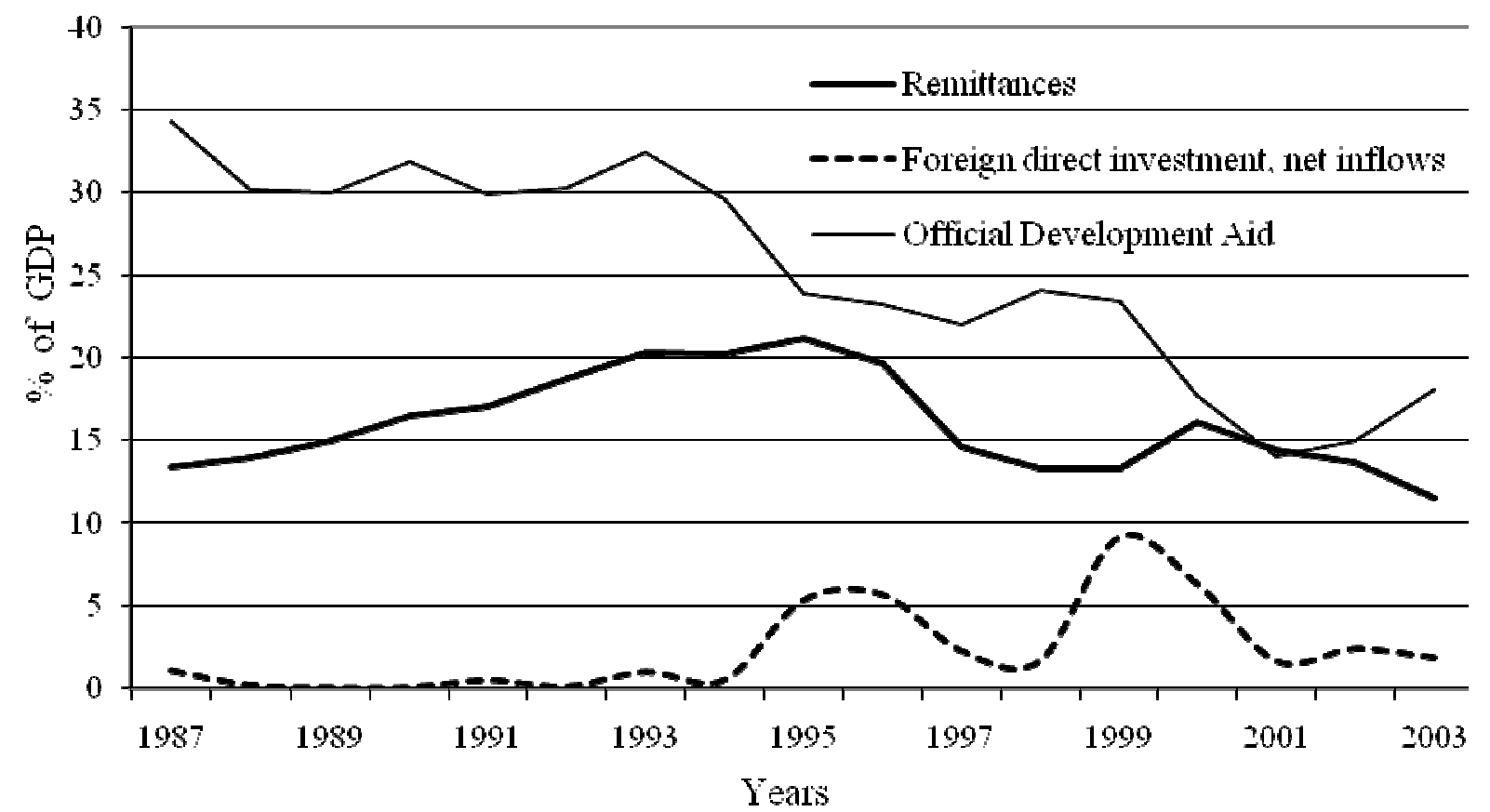

Sonrce: World Bank (2006c). 


\section{Tables}

Table 1: Migration flows and stocks.

Own Survey International Censuses

Flow of emigrants as \% of residents in Cape Verde

Between 2000 and 2005

$3.96 \%$

Between 1995 and 2000

$2.80 \%$

Flow of return migrants as \% of current emigrants

Between 2000 and 2005

$19 \%$

Between 1995 and 2000

$25 \%$

Source: Own survey, INE (2002) and international censuses of destination countries (Portugal, United

States, France, Netherlands, Luxembourg, Italy and Spain) from Ruggles et al. (2004).

Table 2: Main destinations of Cape Verdean emigrants. Percentage of total emigration flows.

\begin{tabular}{lcc}
\hline \hline & $\begin{array}{c}\text { Own Survey } \\
2000-2005\end{array}$ & $\begin{array}{c}\text { Cape Verde Census } \\
1995-2000\end{array}$ \\
\hline Portugal & 54 & 55 \\
US & 21 & 19 \\
France & 12 & 8 \\
Netherlands & 2 & 5 \\
Luxemburg & 2 & - \\
Brazil & 3 & - \\
Other & 6 & 13 \\
\hline \hline
\end{tabular}

Source: Own survey and INE (2002). 
Table 3: Characteristics of individuals born in Cape Verde according to their country of residence and migration status.

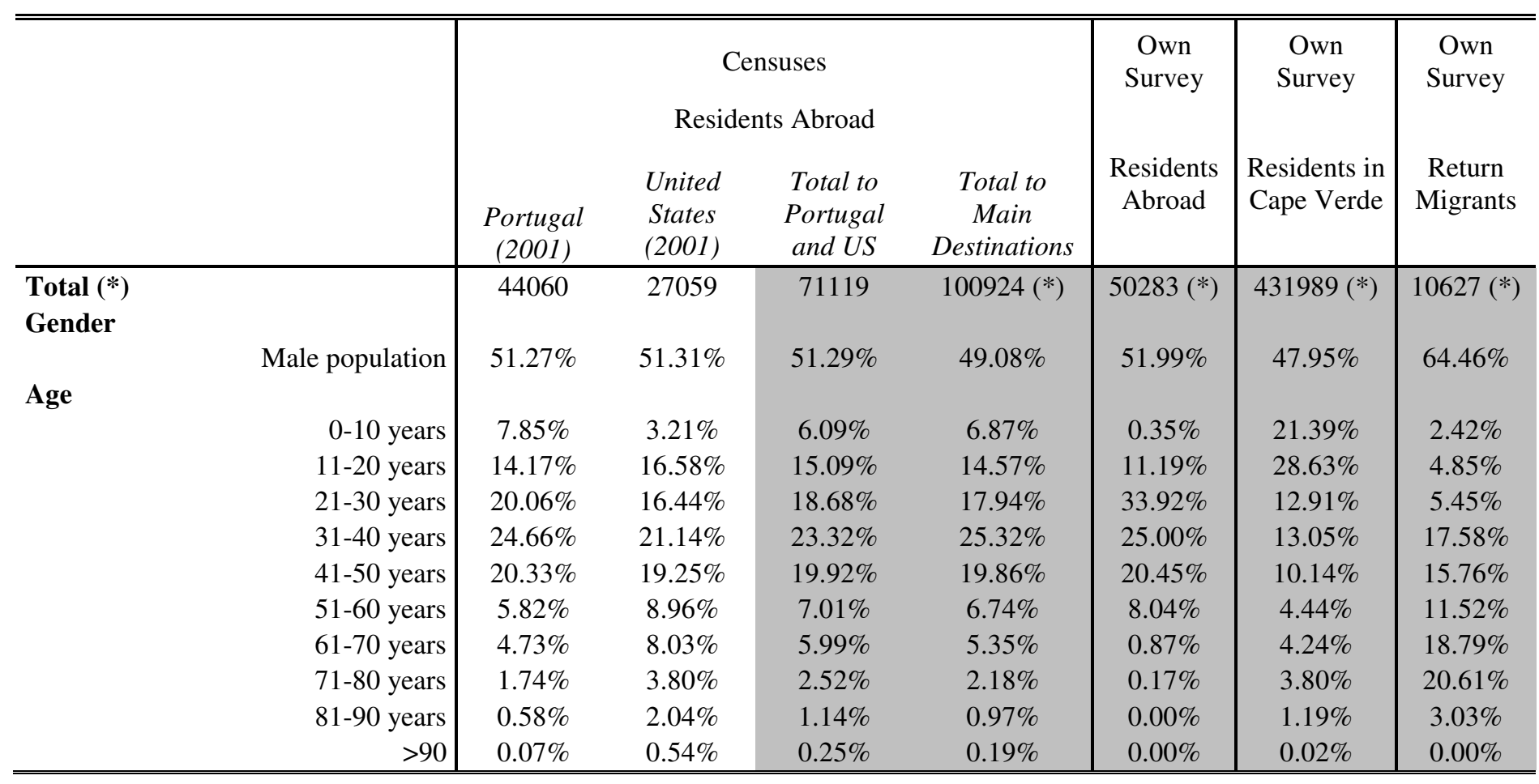

Source: Own survey and international censuses of destination countries (Portugal, United States, France, Netherlands, Luxembourg, Italy and Spain) from Ruggles et al. (2004).

(*) Total number of residents abroad is sum of Cape Verde citizens living abroad divided by 0.92, as detailed in text. Number of residents in Cape Verde from INE (2002) census. Number of residents abroad from the survey uses fraction of residents abroad in total residents (11.64\%). Number of return migrants from the survey uses fraction of return migrants in total residents $(2.46 \%)$.

Table 4: Educational attainment of individuals born in Cape Verde and aged 25 years old or more according to their country of residence.

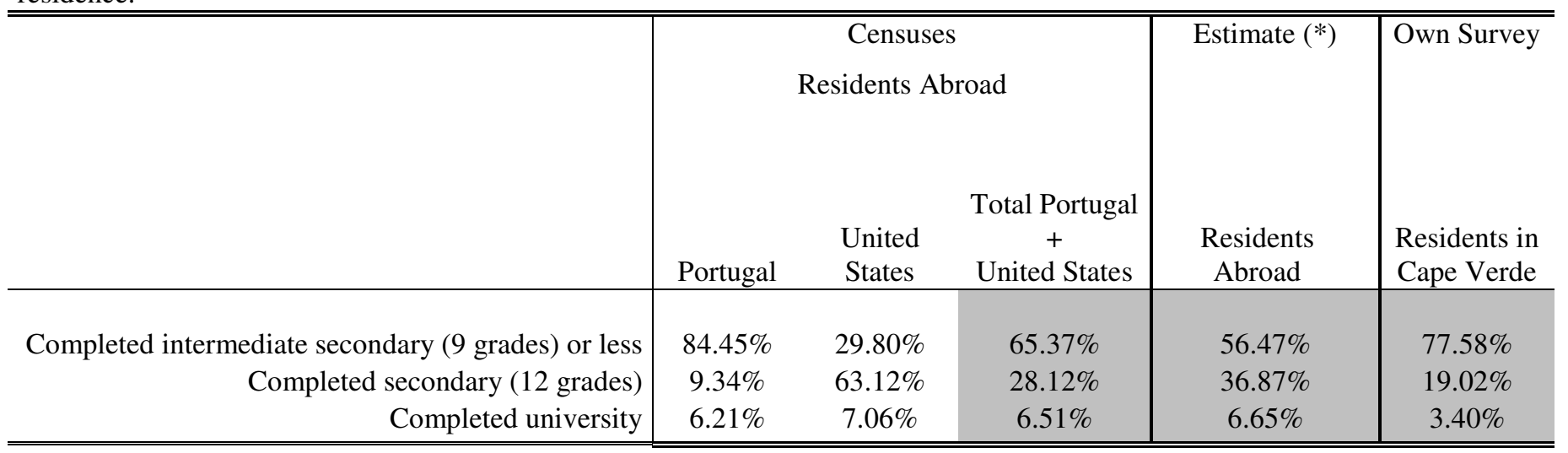

Source: Own survey and international censuses of destination countries (Portugal, United States, France, Netherlands, Luxembourg, Italy and Spain) from Ruggles et al. (2004).

(*) As discussed in the text, it is assumed that $25 \%$ of all emigrants (those who do not emigrate to the United States and Portugal) share the educational attainment of those in the United States. 
Table 5: Difference in mean values of family asset acquisition for an additional year of family migration duration for dependents aged 16 to 30 who did not migrate before age 16 .

\begin{tabular}{lc}
\hline \hline Land or House or Car Acquisition 1997-2005 & -0.0012 \\
Land Acquisition 1997-2005 & $(0.0009)$ \\
& -0.0008 \\
House Acquisition 1997-2005 & $(0.0010)$ \\
Car Acquisition 1997-2005 & 0.0015 \\
& $(0.0020)$ \\
\hline \hline
\end{tabular}

Robust standard errors in parentheses, clustered at household level.

$*$ significant at $10 \%$; * significant at $5 \%$; *** significant at $1 \%$

Table 6: Mean values of family asset acquisition by family migration status for dependents aged 16 to 30 who did not migrate before age 16 and whose parents were both not migrants when dependent was age 12 .

\begin{tabular}{lccc}
\hline \hline & Migrant in the & No Migrant in the & \\
& Family & Family & Difference \\
\hline Land or House or Car Acquisition 1997-2005 & 0.0450 & 0.0582 & -0.0132 \\
& $(0.0140)$ & $(0.0148)$ & $(0.0204)$ \\
Land Acquisition 1997-2005 & 0.0101 & 0.0137 & -0.0033 \\
House Acquisition 1997-2005 & $(0.0273)$ & $(0.0172)$ & $(.0323)$ \\
& 0.0981 & 0.0567 & 0.0414 \\
Car Acquisition 1997-2005 & $(0.0245)$ & $(0.0169)$ & $(0.0298)$ \\
& 0.0695 & 0.0367 & 0.0327 \\
\hline \hline
\end{tabular}

Robust standard errors in parentheses, clustered at household level.

* significant at $10 \%$; ** significant at $5 \%$; *** significant at $1 \%$ 
Table 7: Probability of migration for dependents aged 16 to 30 who did not migrate before age 16 and whose parents were both not migrants when dependent was age 12 .

\begin{tabular}{|c|c|c|c|c|}
\hline & $\begin{array}{c}(1) \\
\text { OLS }\end{array}$ & $\begin{array}{c}(2) \\
\text { PROBIT }\end{array}$ & $\begin{array}{c}(3) \\
\text { OLS }\end{array}$ & $\begin{array}{c}(4) \\
\text { PROBIT }\end{array}$ \\
\hline \multirow{2}{*}{ Duration of migration spell in household at age 12} & 0.0050 & 0.0214 & 0.0047 & 0.0198 \\
\hline & $(0.0015)^{* * *}$ & $(0.0056)^{* * *}$ & $(0.0015)^{* * *}$ & $(0.0056)^{* * *}$ \\
\hline \multirow{2}{*}{ Proportion of migrants in locality } & & & 0.2494 & 1.6416 \\
\hline & & & $(0.1066)^{* *}$ & $(0.6343)^{* * *}$ \\
\hline \multirow{2}{*}{ Male } & -0.0252 & -0.1168 & -0.0268 & -0.1399 \\
\hline & $(0.0185)$ & $(0.1014)$ & $(0.0185)$ & $(0.1021)$ \\
\hline \multirow{2}{*}{ Age } & 0.0899 & 0.7687 & 0.0896 & 0.7652 \\
\hline & $(0.0218)^{* * *}$ & $(0.1384)^{* * *}$ & $(0.0217)^{* * *}$ & $(0.1382)^{* * *}$ \\
\hline \multirow{2}{*}{$\operatorname{Age}^{\wedge} 2$} & -0.0016 & -0.0145 & -0.0016 & -0.0144 \\
\hline & $(0.0005)^{* * *}$ & $(0.0029) * * *$ & $(0.0005)^{* * *}$ & $(0.0029) * * *$ \\
\hline \multirow{2}{*}{ Number of children in household } & -0.0055 & -0.0332 & -0.0051 & -0.0325 \\
\hline & $(0.0033)^{*}$ & $(0.0199)^{*}$ & $(0.0033)$ & $(0.0204)$ \\
\hline \multirow{2}{*}{ Asset ownership } & 0.0492 & 0.3199 & 0.0464 & 0.3120 \\
\hline & $(0.0238)^{* *}$ & $(0.1759)^{*}$ & $(0.0236)^{* *}$ & $(0.1736)^{*}$ \\
\hline \multirow{2}{*}{ Maximum parental education } & 0.0114 & 0.0548 & 0.0112 & 0.0546 \\
\hline & $(0.0031)^{* * *}$ & $(0.0144)^{* * *}$ & $(0.0031)^{* * *}$ & $(0.0144)^{* * *}$ \\
\hline \multirow{2}{*}{ Perceived quality of educational system in Cape Verde } & 0.0057 & 0.0260 & 0.0053 & 0.0276 \\
\hline & $(0.0074)$ & $(0.0418)$ & $(0.0074)$ & $(0.0409)$ \\
\hline \multirow[t]{2}{*}{ Local ratio of educated to non-educated individuals } & 0.1486 & 0.5766 & 0.1437 & 0.4559 \\
\hline & $(0.0893)^{*}$ & $(0.4408)$ & $(0.0894)$ & $(0.4333)$ \\
\hline \multirow{2}{*}{ Local average unemployment } & 0.2322 & 0.7656 & 0.1910 & 0.2004 \\
\hline & $(0.2639)$ & $(1.4026)$ & $(0.2614)$ & $(1.4026)$ \\
\hline Urban, Island Controls & Included & Included & Included & Included \\
\hline F-Statistic on Excluded Instruments & 11.03 & 14.63 & 8.49 & 22.53 \\
\hline Observations & 1423 & 1423 & 1423 & 1423 \\
\hline
\end{tabular}

Robust standard errors in parentheses, clustered at household level.

* significant at $10 \%$; * significant at $5 \%$; *** significant at $1 \%$ 
Table 8: Probability of completing intermediate secondary schooling for dependents aged 16 to 30 who did not migrate before age 16 and whose parents were both not migrants when dependent was age 12 .

\begin{tabular}{|c|c|c|c|c|}
\hline & (1) & $(2)$ & $\begin{array}{c}(3) \\
\text { DPOPIT }\end{array}$ & (4) \\
\hline \multirow{2}{*}{ Own migration } & $\frac{\text { ULS }}{0.1590}$ & $\frac{\text { ULS }}{0.1459}$ & $\frac{\text { PRUBI1 }}{0.4616}$ & $\frac{\text { PROBIT }}{05505}$ \\
\hline & $(0.0406)^{* * *}$ & $(0.0410)^{* * * *}$ & $(0.1319)^{* * *}$ & $(0.1557)^{* * *}$ \\
\hline \multirow[t]{2}{*}{ Male } & & 0.0044 & & -0.0090 \\
\hline & & $(0.0268)$ & & $(0.0850)$ \\
\hline \multirow[t]{2}{*}{ Age } & & 0.0085 & & 0.0058 \\
\hline & & $(0.0316)$ & & $(0.1009)$ \\
\hline \multirow[t]{2}{*}{$\operatorname{Age}^{\wedge} 2$} & & -0.0006 & & -0.0014 \\
\hline & & $(0.0007)$ & & $(0.0022)$ \\
\hline \multirow[t]{2}{*}{ Number of children in household } & & -0.0217 & & -0.0685 \\
\hline & & $(0.0074) * * *$ & & $(0.0219)^{* * *}$ \\
\hline \multirow[t]{2}{*}{ Asset ownership } & & 0.1043 & & 0.3450 \\
\hline & & $(0.0527)^{* *}$ & & $(0.1611)^{* *}$ \\
\hline \multirow[t]{2}{*}{ Maximum parental education } & & 0.0274 & & 0.1039 \\
\hline & & $(0.0038) * * *$ & & $(0.0147)^{* * *}$ \\
\hline \multirow{2}{*}{$\begin{array}{l}\text { Perceived quality of educational } \\
\text { system in Cape Verde }\end{array}$} & & 0.0195 & & 0.0777 \\
\hline & & $(0.0137)$ & & $(0.0422)^{*}$ \\
\hline \multirow{2}{*}{$\begin{array}{l}\text { Local ratio of educated to non- } \\
\text { educated individuals }\end{array}$} & & 0.2823 & & 1.3380 \\
\hline & & $(0.1246)^{* *}$ & & $(0.5271)^{* *}$ \\
\hline \multirow[t]{2}{*}{ Local average unemployment } & & -0.3446 & & 0.0258 \\
\hline & & $(0.4199)$ & & $(1.4418)$ \\
\hline Urban, Island Controls & Not Included & Included & Not Included & Included \\
\hline Observations & 1599 & 1411 & 1599 & 1411 \\
\hline
\end{tabular}

Robust standard errors in parentheses, clustered at household level.

* significant at $10 \%$; * significant at $5 \%$; *** significant at $1 \%$ 
Table 9: Probability of completing intermediate secondary schooling for dependents aged 16 to 30 who did not migrate before age 16 .

\begin{tabular}{|c|c|c|c|c|}
\hline & (1) & (2) & (3) & (4) \\
\hline & 2SLS & $2 \mathrm{SLS}$ & MALLAR & MALLAR \\
\hline \multirow[t]{2}{*}{ Own migration } & 1.1207 & 0.8219 & 0.9310 & 0.7019 \\
\hline & $(0.5177)^{* *}$ & $(0.3832)^{* *}$ & $(0.4216)^{* *}$ & $(0.3047)^{* *}$ \\
\hline \multirow[t]{2}{*}{ Male } & 0.0282 & 0.0127 & 0.0947 & 0.0305 \\
\hline & $(0.0334)$ & $(0.0284)$ & $(0.1006)$ & $(0.0855)$ \\
\hline \multirow[t]{2}{*}{ Age } & -0.0810 & -0.0483 & -0.6689 & -0.4595 \\
\hline & $(0.0598)$ & $(0.0477)$ & $(0.3372)^{* *}$ & $(0.2403)^{*}$ \\
\hline \multirow[t]{2}{*}{$\operatorname{Age}^{\wedge} 2$} & 0.0010 & 0.0004 & 0.0113 & 0.0072 \\
\hline & $(0.0012)$ & $(0.0010)$ & $(0.0064)^{*}$ & $(0.0046)$ \\
\hline \multirow{2}{*}{$\begin{array}{l}\text { Number of children in } \\
\text { household }\end{array}$} & -0.0187 & -0.0221 & -0.0474 & -0.0665 \\
\hline & $(0.0078) * *$ & $(0.0071)^{* * *}$ & $(0.0260)^{*}$ & $(0.0230)^{* * *}$ \\
\hline \multirow[t]{2}{*}{ Asset ownership } & 0.0489 & 0.0510 & 0.0734 & 0.0782 \\
\hline & $(0.0621)$ & $(0.0567)$ & $(0.2183)$ & $(0.2039)$ \\
\hline \multirow[t]{2}{*}{ Maximum parental education } & 0.0162 & 0.0181 & 0.0573 & 0.0616 \\
\hline & $(0.0076)^{* *}$ & $(0.0063)^{* * *}$ & $(0.0279)^{* *}$ & $(0.0248)^{* *}$ \\
\hline \multirow{2}{*}{$\begin{array}{l}\text { Perceived quality of educational } \\
\text { system in Cape Verde }\end{array}$} & 0.0127 & 0.0137 & 0.0491 & 0.0536 \\
\hline & $(0.0145)$ & $(0.0130)$ & $(0.0456)$ & $(0.0428)$ \\
\hline \multirow{2}{*}{$\begin{array}{l}\text { Local ratio of educated to non- } \\
\text { educated individuals }\end{array}$} & 0.1429 & 0.2592 & 0.8968 & 1.3304 \\
\hline & $(0.1622)$ & $(0.1276)^{* *}$ & $(0.6263)$ & $(0.5141)^{* * *}$ \\
\hline \multirow[t]{2}{*}{ Local average unemployment } & -0.6091 & -0.2650 & -0.7270 & 0.4137 \\
\hline & $(0.4896)$ & $(0.4031)$ & $(1.5950)$ & $(1.3562)$ \\
\hline Urban, Island Controls & Included & Included & Included & Included \\
\hline Observations & 1411 & 1541 & 1411 & 1541 \\
\hline
\end{tabular}

Columns (1) and (3) include only dependents whose parents were both not migrants when dependent was 12 years old.

IV: Duration of longest migration spell in household at age 12.

Robust standard errors in parentheses, clustered at household level. Standard errors are bootstrapped for Mallar regressions.

* significant at $10 \% ; * *$ significant at $5 \%$; *** significant at $1 \%$ 
Table 10: Probability of completing intermediate secondary schooling for dependents aged 16 to 30 who did not migrate before age 16 and whose parents were both not migrants when dependent was age 12 .

\begin{tabular}{|c|c|c|c|c|}
\hline & $\begin{array}{c}(1) \\
2 S L S\end{array}$ & $\begin{array}{c}(2) \\
\text { LIML }\end{array}$ & $\begin{array}{c}(3) \\
\text { CUE }\end{array}$ & $\begin{array}{c}(4) \\
\text { MALLAR }\end{array}$ \\
\hline \multirow[t]{2}{*}{ Own migration } & 0.9035 & 0.9989 & 0.8905 & 0.5326 \\
\hline & $(0.4369) * *$ & $(0.5051)^{* *}$ & $(0.4326)^{* *}$ & $(0.2747)^{*}$ \\
\hline \multirow[t]{2}{*}{ Male } & 0.0229 & 0.0253 & 0.0239 & 0.0526 \\
\hline & $(0.0312)$ & $(0.0324)$ & $(0.0311)$ & $(0.0967)$ \\
\hline \multirow[t]{2}{*}{ Age } & -0.0610 & -0.0698 & -0.0603 & -0.3664 \\
\hline & $(0.0529)$ & $(0.0582)$ & $(0.0526)$ & $(0.2335)$ \\
\hline \multirow[t]{2}{*}{$\operatorname{Age}^{\wedge} 2$} & 0.0006 & 0.0008 & 0.0006 & 0.0056 \\
\hline & $(0.0011)$ & $(0.0012)$ & $(0.0011)$ & $(0.0045)$ \\
\hline \multirow{2}{*}{ Number of children in household } & -0.0193 & -0.0190 & -0.0197 & -0.0551 \\
\hline & $(0.0075)^{* *}$ & $(0.0077)^{* *}$ & $(0.0075)^{* * *}$ & $(0.0246)^{* *}$ \\
\hline \multirow{2}{*}{ Asset ownership } & 0.0613 & 0.0558 & 0.0670 & 0.1931 \\
\hline & $(0.0585)$ & $(0.0606)$ & $(0.0581)$ & $(0.1906)$ \\
\hline \multirow[t]{2}{*}{ Maximum parental education } & 0.0187 & 0.0176 & 0.0183 & 0.0775 \\
\hline & $(0.0067)^{* * *}$ & $(0.0075)^{* *}$ & $(0.0067)^{* * *}$ & $(0.0226)^{* * *}$ \\
\hline \multirow{2}{*}{$\begin{array}{l}\text { Perceived quality of educational system in } \\
\text { Cape Verde }\end{array}$} & 0.0142 & 0.0136 & 0.0175 & 0.0584 \\
\hline & $(0.0137)$ & $(0.0140)$ & $(0.0135)$ & $(0.0447)$ \\
\hline \multirow{2}{*}{$\begin{array}{l}\text { Local ratio of educated to non-educated } \\
\text { individuals }\end{array}$} & 0.1739 & 0.1603 & 0.1779 & 1.2208 \\
\hline & $(0.1497)$ & $(0.1561)$ & $(0.1490)$ & $(0.6009)^{* *}$ \\
\hline \multirow[t]{2}{*}{ Local average unemployment } & -0.5501 & -0.5760 & -0.5201 & -0.0815 \\
\hline & $(0.4589)$ & $(0.4724)$ & $(0.4571)$ & $(1.5879)$ \\
\hline Urban, Island Controls & Included & Included & Included & Included \\
\hline Observations & 1411 & 1411 & 1411 & 1411 \\
\hline
\end{tabular}

IVs: Duration of longest migration spell in household at age 12; Proportion of migrants in locality.

Robust standard errors in parentheses, clustered at household level. Standard errors are bootstrapped for Mallar regressions.

* significant at $10 \%$; * significant at $5 \%$; *** significant at $1 \%$ 
Table 11: Probability of completing intermediate secondary schooling for dependents aged 16 to 30 who never emigrated and whose parents were both not migrants when dependent was age 12 .

\begin{tabular}{|c|c|c|c|c|}
\hline & (1) & (2) & (3) & (4) \\
\hline & 2SLS & MALLAR & 2SLS & MALLAR \\
\hline \multirow{2}{*}{ Own migration } & 1.2522 & 0.8924 & 0.8954 & 0.4901 \\
\hline & $(0.6367)^{* *}$ & $(0.4629)^{*}$ & $(0.5000)^{*}$ & $(0.2933)^{*}$ \\
\hline \multirow[t]{2}{*}{ Male } & 0.0396 & 0.1116 & 0.0310 & 0.0717 \\
\hline & $(0.0318)$ & $(0.1035)$ & $(0.0313)$ & $(0.0992)$ \\
\hline \multirow{2}{*}{ Age } & -0.0962 & -0.6588 & -0.0638 & -0.3518 \\
\hline & $(0.0656)$ & $(0.3645)^{*}$ & $(0.0556)$ & $(0.2439)$ \\
\hline \multirow{2}{*}{$\mathrm{Age}^{\wedge} 2$} & 0.0012 & 0.0109 & 0.0006 & 0.0051 \\
\hline & $(0.0013)$ & $(0.0069)$ & $(0.0011)$ & $(0.0047)$ \\
\hline \multirow{2}{*}{ Number of children in household } & -0.0202 & -0.0523 & -0.0214 & -0.0605 \\
\hline & $(0.0084)^{* *}$ & $(0.0272)^{*}$ & $(0.0081)^{* * *}$ & $(0.0250)^{* *}$ \\
\hline \multirow{2}{*}{ Asset ownership } & 0.0332 & 0.0232 & 0.0503 & 0.1448 \\
\hline & $(0.0644)$ & $(0.2307)$ & $(0.0612)$ & $(0.1982)$ \\
\hline \multirow{2}{*}{ Maximum parental education } & 0.0138 & 0.0494 & 0.0178 & 0.0698 \\
\hline & $(0.0086)$ & $(0.0299)^{*}$ & $(0.0074)^{* *}$ & $(0.0238) * * *$ \\
\hline \multirow{2}{*}{$\begin{array}{l}\text { Perceived quality of educational system in } \\
\text { Cape Verde }\end{array}$} & 0.0087 & 0.0340 & 0.0109 & 0.0431 \\
\hline & $(0.0149)$ & $(0.0463)$ & $(0.0147)$ & $(0.0456)$ \\
\hline \multirow{2}{*}{$\begin{array}{l}\text { Local ratio of educated to non-educated } \\
\text { individuals }\end{array}$} & 0.1605 & 0.8664 & 0.2132 & 1.1981 \\
\hline & $(0.1744)$ & $(0.6575)$ & $(0.1632)$ & $(0.6245)^{*}$ \\
\hline \multirow{2}{*}{ Local average unemployment } & -0.6862 & -1.2341 & -0.5801 & -0.5662 \\
\hline & $(0.4726)$ & $(1.6164)$ & $(0.4635)$ & $(1.6140)$ \\
\hline Urban, Island Controls & Included & Included & Included & Included \\
\hline Observations & 1242 & 1242 & 1242 & 1242 \\
\hline
\end{tabular}

IV: "Duration of longest migration spell in household at age 12" in columns (1) and (2). "Duration of longest migration spell in household at age 12" and "Local proportion of migrants" in columns (3) and (4).

Robust standard errors in parentheses, clustered at household level. Standard errors are bootstrapped for Mallar regressions.

* significant at $10 \%$;* significant at $5 \%$; *** significant at $1 \%$ 
Table 12: Counterfactual educational attainment of individuals born in Cape Verde aged 16 to 30 who did not migrate before age 16.

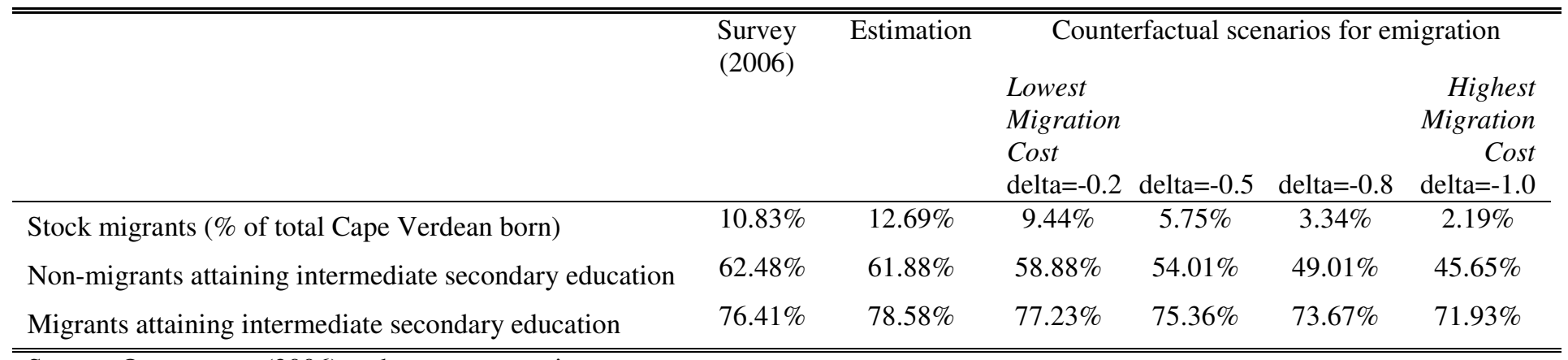

Source: Own survey (2006) and own computations.

Table 13: Counterfactual educational attainment of all individuals born in Cape Verde aged 16 to 30 . Reweighted in order to account for individuals missing in the survey. $(*)$

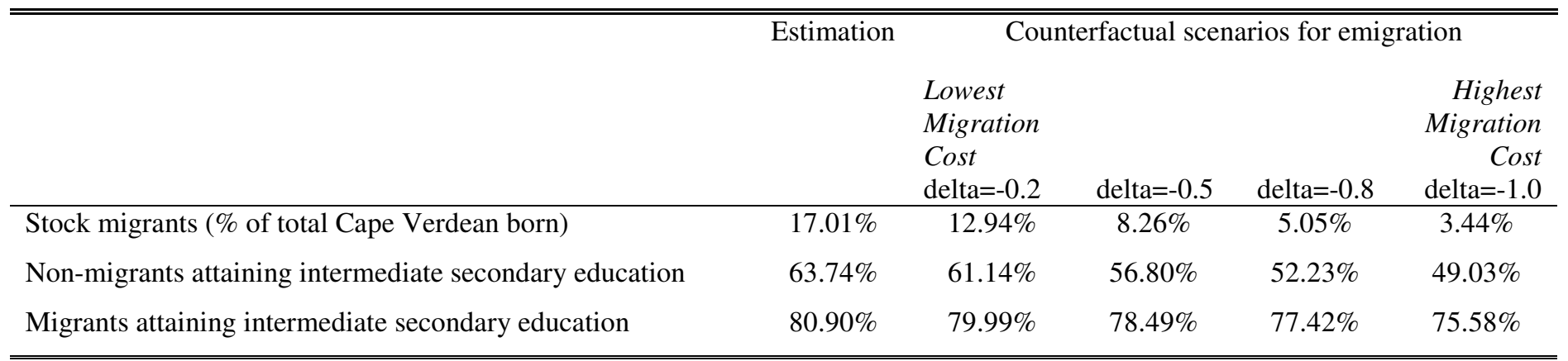

Source: Own survey (2006), Ruggles et al. (2004) and own computations.

(*) Individuals missing in the survey are those migrants who migrated before age 16 and are currently aged 16 to 30 years old.

Table 14: Average annual wages of Cape Verdean. Males between 25 and 50 years old.

\begin{tabular}{|c|c|c|c|}
\hline & Cape Verde & US & Difference \\
\hline \multicolumn{4}{|c|}{ US Dollars (nominal exchange rate) } \\
\hline 9 years of schooling or less & 1975.6 & 18262.5 & 16286.9 \\
\hline \multirow[t]{2}{*}{ More than 9 years of schooling } & 3789.3 & 24658.0 & 20868.7 \\
\hline & & & 4581.8 \\
\hline \multicolumn{4}{|c|}{ International Dollars (PPP-adjusted) } \\
\hline 9 years of schooling or less & 6378.4 & 18262.5 & 11884.1 \\
\hline \multirow[t]{2}{*}{ More than 9 years of schooling } & 12234.1 & 24658.0 & 12423.9 \\
\hline & & & 539.8 \\
\hline
\end{tabular}

Source: Own computations based on data from Ruggles et al. (2004) for the US and INE (2004) for Cape Verde. Original numbers adjusted using nominal and PPP exchange rates from WDI (2006). 